\title{
DINÂMICA POPULACIONAL DE Monalonion annulipes SIGNORET, 1858 (HEMIPTERA: MIRIDAE) EM CACAUEIROS DE ARIQUEMES, RO
}

\author{
OLZENO TREVISAN
}

Engenheiro Agrônomo

Orientador: Prof. Dr. SINVAL SILVEIRA NETO

Tese apresentada à Escola Superior de Agricultura "Luiz de Queiroz", Universidade de São Paulo. para obtenção do título de Doutor em Ciências, Área de Concentração: Entomologia.

PIRACICABA

Estado de São Paulo - Brasil

Setembro - 1998 


\section{Errata}

Página Onde está escrito

vi Figura 4.2. ... diferentes hospedeiros. Oeste, RO, 1997. Temperatura $24 \pm 2^{\circ} \mathrm{C}$, UR: $75 \pm 5 \%$ e fotofase 13 horas.

vii 5.1 Distribuição dos ninhos de Figura 5.1. Distribuição dos ninhos de formiga E. tuberculatum em uma' formiga Ectatomma tuberculatum (os área de 2,5 hectares de cacaueiros em pontos referem-se aos ninhos) em uma Ouro Preto do Oeste, RO área de 2,5 hectares de cacaueiros em Ouro Preto do Oeste, RO.

vii Nos Ítens 5.3 e 5.5: E. tubrculatum E. tuberculatum

15 Juno

Junho

20 od danos

os danos

$21 \quad 19973$

1973

39

$$
\frac{r a-r e}{\text { ore }} \text { com ore }(5 \%)=1,96
$$

43

4,8

46 foram observados formigas

60 biologiy $\frac{r a-r e}{\alpha_{r e}} \operatorname{com} \alpha_{r e}{ }^{(5 \%)=1,96}$

4,8

foram observadas formigas biology 
Dados Internacionais de Catalogação na Publicação (CIP) DIVISĀO DE BIBLIOTECA E DOCUMENTACĀO - Campus "Luiz de OUeirOz"/USP

Trevisan, Olzeno

Dinámica populacional de Monalonion annulipes Signoret, 1858 (Hemiptera:

Miridae) em cacaueiros de Ariquemes, RO / Olzeno Trevisan. - - Piracicaba, 1998.

60 p. : il.

Tese (doutorado) - Escola Superior de Agricultura Luiz de Queiroz, 1998.

Bibliografia.

1. Cacau 2. Dinámica podulacional 3. Inseco-para-controle-biolćgico 4. Percevejo

5. Planta hospedeira 6. Praga agricola 1. Titulo

$\operatorname{CDD} 633.74$ 


\section{AGRADECIMENTOS}

Ao Prof. Dr. Sinval Silveira Neto, pela orientação, amizade, compreensão e apoio constante transmitido durante o curso.

Aos professores do Departamento de Entomologia (ESALQ/USP), pelos valiosos conhecimentos adquiridos no decorrer do curso.

À Comissão Executiva do Plano da Lavoura Cacaueira CEPLAC, pela liberação para o curso e apoio para a elaboração e execução da presente pesquisa.

Ao Conselho Nacional de Desenvolvimento Científico e Tecnológico CNPq, pela bolsa de estudo que possibilitou a execução desse trabalho.

Ao Prof. Dr. José Djair Vendramim pelo apoio, sugestões e amizade.

À equipe de extensionistas, técnicos da Estação Experimental da CEPLAC em Rondônia pela amizade e inestimável ajuda na execução da pesquisa.

Ao Prof. Dr. João Roberto Spotti Lopes, pela elaboração do "Summary".

Ao Dr. Antônio Carlos de Barros Mendes da CEPLAC, Belém pelas sugestões e estímulo recebido.

Ao Dr. Jacques Hubert Charles Delabie da CEPLAC, Bahia e Dr. Luiz Antonio Alves Costa do Museu Nacional, Rio de Janeiro, pela identificação dos insetos.

Ao Prof. Dr. José Eduardo Corrente e Dra. Marinéia de Lara Haddad pela orientação nas análises estatísticas. 


\section{SUMÁRIO}

Página

LISTA DE FIGURAS .............................................................................. vi

LISTA DE TABELAS............................................................................ viii

RESUMO

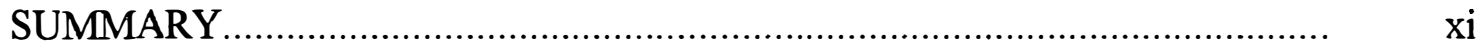

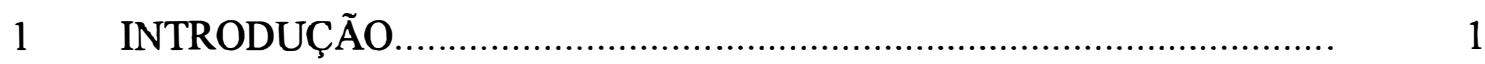

2 REVISÃO DE LITERATURA.......................................................... 2

2.1 Gênero Monalonion: histórico, ocorrência, danos e controle.................... 2

2.2 Preferência alimentar de M. annulipes....................................................

2.3 Atividade da formiga E. tuberculatum Oliver.......................................... 7

3 DINÂMICA POPULACIONAL DE Monalonion annulipes SIGNORET, 1858 (HEMIPTERA: MIRIDAE) EM CACAUEIROS DE ARIQUEMES, RO................................................................ 9

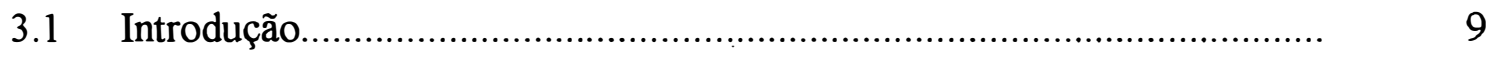

3.2 Material e Métodos ....................................................................... 10

3.3 Resultados e discussão.................................................................. 12

3.3.1 Ataque de M. annuiipes na frutifícaçào do cacaueiro............................. 12

3.3.2 Lançamento de ramos novos de cacaueiro e danos de M. annulipes........ 21

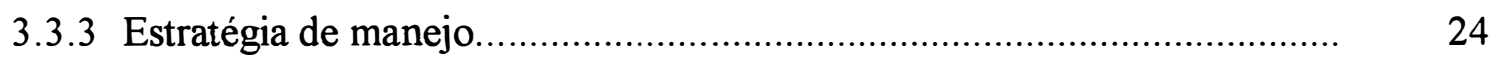

4 PREFERÊNCIA ALIMENTAR DE Monalonion annulipes Signoret, 1858 (HEMIPTERA: MIRIDAE) EM HOSPEDEIROS

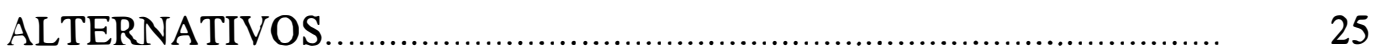

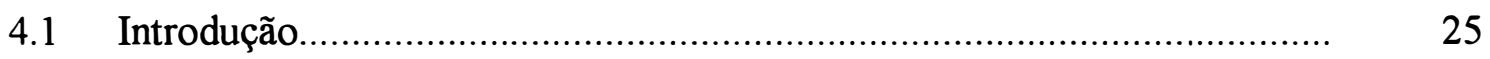

4.2 Material e métodos........................................................................ 26

4.2.1 Hospedeiros alternativos ................................................................ 26

4.2.2 Teste de preferência alimentar................................................................ 27

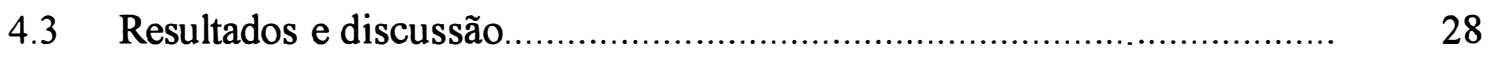




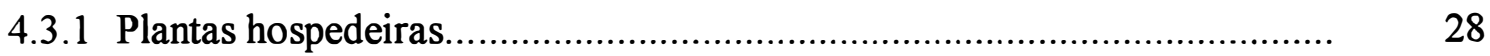

4.3.2 Preferência alimentar...................................................................... 32

5 ATIVIDADE DA FORMIGA Ectatomma tuberculatum OLIV. PARA O CONTROLE DO MONALÔNIO DO CACAU................................... 37

5.1 Introdução................................................................................. 37

5.2 Material e Métodos........................................................................ 38

5.2.1 Distribuição dos ninhos da formiga E. tuberculatum em cacaueiros...... 38

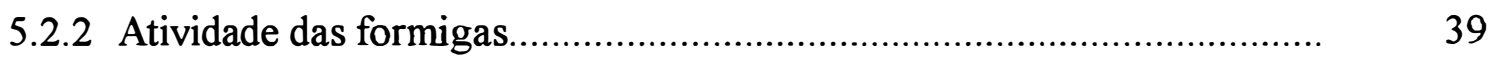

5.2.3 Capacidade da formiga E. tuberculatum em evitar danos de monalônio 40

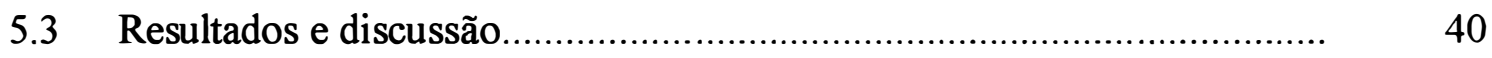

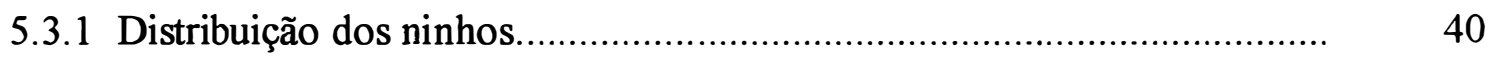

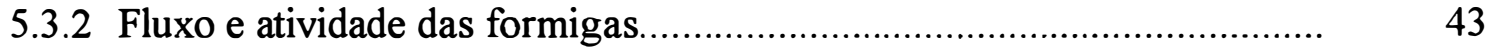

5.3.3 Capacidade da formiga E. tuberculatum em evitar danos de monalônio. 46

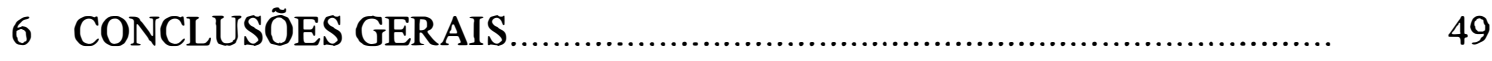

REFERÊNCIAS BIBLIOGRÁFICAS................................................... 51 


\section{LISTA DE FIGURAS}

Página

3.1 Frutos de cacau protegidos para avaliação de danos de M. annulipes................ 11

3.2 Cacaueiro protegido para avaliação do comportamento de M. annulipes........... 11

3.3 Umidade relativa e flutuação populacional de M. annulipes em cacauais, Ariquemes, RO. Médias mensais, março de 1990 a março de 1993................... 13

3.4 Disponibilidade de frutos de cacaueiro em diferentes fases de desenvolvimento. Ariquemes, RO. Médias mensais, março de 1990 a março de $1993 . . . . .$.

3.5 Porcentagem de frutos de cacaueiro atacados por M. annulipes em diferentes estágios de desenvolvimento. Ariquemes, RO. Médias mensais, 1990 a 1993.16

3.6 Ninfas de M. annulipes em diferentes fases de desenvolvimento $(\mathrm{A}, \mathrm{B}, \mathrm{C}, \mathrm{D}, \mathrm{E})$ e adultos em cópula $(\mathrm{F})$

3.7 Ataque de M. annulipes em cacau: (A) deformação, rachaduras e mumificação em frutos em desenvolvimento; (B) fruto mumificado e com rachadura; (C) frutos desenvolvidos e infectados por fungos após danos do inseto e (D) cacaueiro com frutos atacados. Ouro Preto do Oeste, RO.1998

3.8 Frutos de cacau maduros atacados por M. annulipes após completado o seu desenvolvimento. Ouro Preto do Oeste, Rondônia

3.9 Precipitação pluviométrica, lançamento de ramos de cacaueiro e ataque de $M$. annulipes em Ariquemes, RO. Médias mensais, março de 1990 a março de 1993 ..

3.10 Danos de M. annulipes em lançamentos de ramos de cacaueiro. Ouro Preto do Oeste, Rondônia.

4.1 Gaiola utilizada para a avaliação da preferência alimentar de M. annulipes...

4.2 Índice de preferência de M. annulipes em diferentes hospedeiros. 
4.3 Danos de M. annulipes em frutos de cacaueiro e goiabeira. Ouro Preto do Oeste, RO. 1997...................................................................................

4.4 Danos de M. annulipes em frutos de cajueiro e cupuaçuzeiro. Ouro Preto do Oeste, RO. 1997.

5.1 Distribuição dos ninhos de formiga E. tuberculatum em uma área de 2,5 hectares de cacaueiros em Ouro Preto do Oeste, RO.

5.2 Análise estatística pelo teste de Kolmogorov-Smirnov da distribuição de ninhos de formiga E. tuberculatum, em cacauais de Ouro Preto do Oeste, RO.......... 42

5.3 Formiga E. tuberculatum tentando capturar uma lagarta..................................... 45

5.4 Entrada de um ninho de E. tubrculatum na base de um cacaueiro. 45

5.5 Ação da formiga E. tubrculatum sobre ataque de monalônio em frutos de cacau em plantas com ninho da formiga, plantas próximas $(3 \mathrm{~m})$ e afastadas (mais de 9 m). Ouro Preto do Oeste, RO. 1998. 


\section{LISTA DE TABELAS}

Página

3.1 Frutos de cacaueiro encontrados em diferentes fases de desenvolvimento. Ariquemes, RO. Médias mensais, março de 1990 a março de 1993

3.2 Porcentagem de frutos de cacaueiro atacados por M. annulipes em diferentes estágios de desenvolvimento. Ariquemes, RO. Médias mensais, 1990 a $1993 \ldots 16$

4.1 Danos de alimentação de $M$. annulipes em teste com livre chance de escolha entre fruteiras, ocorrência natural do inseto no campo e sobrevivência no hospedeiro. Julho a agosto de 1997. Ouro Preto do Oeste, RO............................................... 29

4.2 Espécies válidas de insetos do gênero Monalonion e suas plantas hospedeiras ... 31

5.1 Distribuição de freqüências observadas em ninhos de formiga E. tuberculatum para o teste do vizinho mais próximo, em plantios de cacau em Ouro Preto do Oeste, RO. 1997

5.2 Fluxo da formiga E. tuberculatum que entraram no ninho por hora. Ouro Preto do Oeste, RO. 1997. 


\title{
DINÂMICA POPULACIONAL DE Monalonion annulipes SIGNORET, 1858 (HEMIPTERA: MIRIDAE) EM CACAUEIROS DE ARIQUEMES, RO
}

\author{
Autor: OLZENO TREVISAN \\ Orientador: Prof. SINVAL SILVEIRA NETO
}

RESUMO

A população de Monalonion anmulipes amostrada em cacauais de Ariquemes, Rondônia coincidiu com a frutificação da safra principal para as diferentes categorias de frutos em desenvolvimento. As maiores porcentagens de frutos danificados de cacaueiros ocorreram de maio a julho e foram: $5,7 \%$ de bilros; $15,7 \%$ de frutos pequenos; $32,6 \%$ de frutos médios; $35,6 \%$ de frutos verdes; $37,8 \%$, de frutos maduros. A renovação foliar dos cacaueiros foi mais intensa nos meses de janeiro, maio $e_{\text {a agosto. }}$ As plantas hospedeiras de monalônio foram investigadas em observações de campo e se constataram novos hospedeiros para a praga na região. Em testes de preferência obtiveram-se os seguintes índices: $100 ; 27,6 ; 11,9 ; 7,5 ; 1,3$ e $0,6 \%$, respectivamente para frutos de cacau, cupuaçu, caju, banana, goiaba, graviola, além de cruá, araçá-pera, cacauí e manga, sem determinação do índice de preferência. A formiga, Ectatomma tuberculatum, foi considerada o principal inimigo natural do $M$. annulipes nos cacaueiros onde estava estabelecida. $\mathrm{O}$ predador apresentou distribuição dos ninhos do tipo agregada em $10 \%$ das árvores avaliadas. As principais atividades das formigas no cacaueiro durante o dia, no período seco para a região foram: busca, espera, mutualismo, 
vigilância e suprimento de água. A formiga foi capaz de evitar danos nos frutos de cacau aumentando a quantidade de frutos sadios nas plantas onde construiu ninhos. Foram também questionados os métodos tradicionais de controle de pragas na cultura e sugeriuse que fossem consideradas, as formigas predadoras, dentro de um programa de manejo de pragas do cacaueiro. 


\title{
POPULATION DYNAMIC OF Monalonion annulipes SIGNORET, 1858 \\ (HEMIPTERA: MIRIDAE) ON CACAO TREES IN ARIQUEMES, STATE OF \\ RONDONIA, BRAZIL.
}

\author{
Author: OLZENO TREVISAN \\ Adviser: Prof. Dr. SINVAL SILVEIRA NETO
}

\section{SUMMARY}

Occurrence of Monalonion annulipes in cacao plantations from Ariquemes (RO) was coincident with the main fruit season for the different categories of developing fruits. The highest rates of damaged fruits were observed from May to June, reaching levels of: $5.7 \%$ in young fruits ('bilros'), $15.7 \%$ in small fruits, $32.6 \%$ in medium-size fruits, $35.6 \%$ in green fruits and $37.8 \%$ in ripe fruits. The renovation of leaves in the cacao trees was more intense in January, May and August. A search for host plants of M. annulipes was carried out in the field and new host species were found in the region. Indices obtained in feeding preference tests were $100,27.6,11.9,7.5,1.3$ and 0.6 for Theobroma cacao, 1 . grandiflorum, Anacardium occidentale, Musa sp., Psidium guajava and Annona muricata, respectively. The ant Ectatomma tuberculatum was considered as the main natural enemy of $M$. annulipes on trees where this pest was established. Spatial pattern of ant nests was aggregated in $10 \%$ of sampled trees. The main ant activities on the cacao tree during the day, in the dry season were: search, wait, mutualism, vigilance and water supply. Ants were able to prevent fruit damage by the pest. As a result, nest-bearing trees produced a larger number of undamaged fruits. This research points out the potential role of predator ants for the integrated pest management in cacao, and the need to review traditional pest control methods in order to preserve ant populations. 


\section{INTRODUÇÃO}

O mirídeo Monalonion annulipes Signoret, 1858 ocorre há muitos anos na América Central e tem causado danos nos cacauais da Costa Rica (Villacorta, 1967). Sua presença na Amazônia e outros países da América do Sul e Central foi assinalada por Carvalho (1972). Segundo Mendes et al. (1979), o inseto era pouco disseminado na Amazônia e sua ocorrência em cacau somente havia sido notada nos pólos cacaueiros de Rondônia e em dois locais no Pará, porém o seu ataque em cacaueiros de Rondônia tem aumentado nos últimos anos a ponto de ser considerado uma das principais pragas. Desta forma, a falta de uma proteção adequada da lavoura por instabilidade econômica da cultura na região foi, provavelmente, um dos fatores que mais prejudicaram a cacauicultura, favorecendo o aumento populacional e dispersão de pragas na região. Portanto, além dos conhecimentos básicos de ecologia, plantas hospedeiras, inimigos naturais e fenologia da planta já efetuados em parte por Alvim et al. (1974) e Abreu (1979) na Bahia; Mendes \& Garcia (1983) e Mendes et al. (1997) para outras espécies de insetos no Pará, outros estudos envolvendo principalmente controle e prejuízos precisam ser feitos para esse mirídeo em Rondônia. Para tanto é fundamental apresentar além do controle químico, métodos alternativos que solucionem o problema para evitar grandes perdas. Assim, o presente trabalho teve por objetivo: determinar a flutuação populacional e danos de $M$. annulipes relacionado à fenologia do cacaueiro, encontrar e identificar hospedeiros alternativos e determinar um Índice de Preferência entre as plantas danificadas pelo inseto, determinar o principal inimigo natural e avaliar a sua eficiência para controle da praga. 


\section{REVISÃO DE LITERATURA}

\subsection{Gênero Monalonion: histórico, ocorrência, danos e controle}

A denominação popular aos ataques de insetos do gênero Monalonion pode variar dependendo do local. Em Rondônia, é comum a denominação "monalônio", mas para Bahia a e outras regiões recebe vários nomes: "chupança", "chupança do cacau", "bexiga" e "bexiga do cacau" em conseqüência dos danos que causa nos frutos. Quando o ataque ocorre nos ramos novos recebe normalmente a denominação de "queima", "emponteiramento" ou "morte descendente" ("die-back"), em conseqüência da morte dos pontos de crescimento e queda das folhas (Lima, 1938; Abreu, 1977). Em outros países é mais conhecido pelas denominações: "chinche"; "grajo amarillo"; "mosquilla"; "capsidio del cacao" e "die-back" (Hernandez, et al., 1958; Cubillos, 1984; Morales \& Matarita, 1961).

O conhecimento das espécies de mirídeos associadas ao cacaueiro no Brasil iniciou-se com a descrição do gênero Monalonion, para M. parviventre Herrich-Schffer, 1853, baseado em um exemplar fêmea do Brasil e M. annulipes Signoret, 1858 descrita baseada num exemplar proveniente do México e depositado no Museu de Berlim. Com base nas informações disponíveis dos registros desses insetos em cacau, constata-se que muitos nomes atribuídos a espécies desse gênero não são considerados válidos (Carvalho, 1972).

A importância desses insetos como pragas do cacaueiro foi primeiro citada para a Bahia, quando o Pe. Leo Zehntener observou danos característicos em frutos de cacau 
e Torrend (1918) denomina o inseto provisoriamente de Mosquilla vastatrix por ser idêntico a um inseto conhecido, no Equador, por "mosquilla". Porém Bondar (1937) constatou que o mirídeo pertencia ao gênero Monalonion e denominou-o $M$. xanthophyllum, que na revisão de Carvalho (1972) caiu em sinonímia de M. shaefferi Stäl, 1860. Lima (1938) listou 15 espécies para o gênero, sendo seis encontradas em cacau. O inseto de Rondônia foi citado em cacau na Costa Rica em 1964 (Ventocilla, 1967). Embora Carvalho (1972) tenha citado a sua ocorrência na Amazônia brasileira, Colômbia, Equador, Guianas, México, Guatemala, Panamá e Venezuela, o inseto não foi considerado problema para a cultura do cacau no Brasil. Para o autor, das 25 espécies citadas na época, somente 11 foram consideradas válidas.

Em estudos posteriores de Entwistle (1972); Abreu (1977); Carvalho (1985;1990); Carvalho \& Costa (1988); Trevisan \& Mendes (1993) e Mendes (1995) novas espécies foram encontradas e outras entraram em sinonímia, de tal forma que resumindo as informações desses autores as espécies válidas com suas sinonímias e locais de ocorrência seriam:

\section{Espécies e sinonímias}

1 - M. annulipes Signoret, 1858.

Sinonímias:

M. bothrocranum Reuter, 1908

M. braconoides Walker, 1873

M. ichneumonoides Walker, 1873

M. illustris Distant, 1917

M. reuteri, 1910

2 - M. atratum Distant, 1883.

Sinonímias:

M. bahiense Costa Lima, 1938

\section{Locais de ocorrência}

No Brasil: AC, AM, AP, MG, RO, RR, PA, SP; Guiana

Francesa, Peru, Colômbia, Guatemala, México, Panamá e Costa Rica. 
M. knighti Bondar, 1939

M. pilosipes Kirkaldy, 1902

3 - M. bicolor Carvalho \& Costa, 1988

Costa Rica

4- M. bondari Costa Lima, 1938

Brasil: BA

5- M. columbiensis Carvalho, 1984

Colômbia

6- M. decoratum Monte, 1942

Brasil: AM, GO; Peru, Bolívia

7 - M. dissimulatum Distant, 1883.

Brasil: AM; Guatemala, Suri-

Sinonímias:

name, Venezuela, Colômbia,

M. collaris Distan, 1917

Peru, Equador e Bolívia.

M. megiston Kirkaldy , 1902

8 - M. incaicus Carvalho, 1972

Peru.

9 - M. itabunensis Carvalho, 1972

$10-$ M. kirkaldy Bondar, 1939

Brasil: BA e PA; Colômbia.

Brasil: BA.

11 - M. paraensis Carvalho 1985

Brasil: AP, PA.

$12-$ M. parviventre Herr.-Sch., 1853

Brasil: PR, SC; Paraguai.

13 - M. peruvianus Kirdaldy, 1907.

Peru.

Sinonímia:

M. aimaranus Carvalho,1972

15 - M. velezangeli Carvalho \& Costa, 1988

Colômbia.

16-M. versicolor Distant, 1883.

Guatemala

Sinonímia:

M. hilaratum Distant, 1883 (sexo oposto) 
17 - M. schaefferi Stal, 1860.

Brasil: BA, RJ.

Sinonímias:

M. flavisignatum Kirkaldy, 1937

Mosquilla vastatrix Torrend \& Zehntner, 1917

M. flavisignatum Knight, 1939

M. xanthophilum (Walker,1873)

A biologia dos mirídeos do cacaueiro foi estudada por Eguagie (1977) sendo assunto de uma revisão efetuada por Entwistle (1985) onde comenta a falta de conhecimentos da biologia desses insetos, principalmente pela dificuldade em se manter populações em condições de laboratório.

Quanto aos danos de M. annulipes em cacaueiros, são relatadas perdas por danos diretos e indiretos como conseqüência do ataque do inseto, que ao iniciar o ato alimentar, injeta uma saliva tóxica no local de alimentação, causando a morte dos tecidos atingidos. Além dos danos em forma de "bexiga" deixados nos frutos e morte de brotos novos, na Costa Rica, está associado à morte descendente do cacaueiro (Villacorta, 1973). Para outras espécies do gênero desse inseto, foram registrados danos em cacaueiros causados pela penetração dos fungos dos gêneros Colletotrichum e Fusarium (Morales \& Matarita, 1961) e lesões em ramos terminais também foram invadidas pela alga Cepharleuras mycoides (Silva, 1957). Em Rondônia, Bastos \& Evans (1979) isolaram os fungos Botrytodiplodia theobromae e Phomopsis folliculicolla de plantas picadas por insetos. Rodrigues et al. (1993) citaram vários fungos associados às lesões de $M$. bondari em cacaueiros na Bahia. Verificou-se que os danos de Monalonion em frutos de cacau, inicialmente relatados não foram suficientemente investigados, sendo tomadas como básicas as informações de Silva (1944) que citou não ocorrerem danos quando frutos de cacau com $8 \mathrm{~cm}$ ou mais de diâmetro são atacados e que $o$ ataque em frutos maiores geralmente produzem amêndoas atrofiadas e de menor 
tamanho (Hernandez et al., 1958). Não havendo também informações que quantificam o ataque do M. annulipes nas diferentes fases de desenvolvimento dos frutos de cacau.

A avaliação da flutuação populacional de monalônio em cacaueiro serve para auxiliar na execução racional de qualquer programa de controle de pragas. Os primeiros estudos realizados para M. annulipes na Costa Rica por Villacorta (1967) indicaram que a população foi maior em cacaueiros a pleno sol do que àqueles em área sombreada. Tanto nos cacaueiros sombreados como naqueles desprovidos de sombreamento a população apresentou um pico por ano durante os meses de outubro e novembro. A alta incidência do inseto estaria relacionada com a disponibilidade de alimento e alta umidade relativa no período que, de modo semelhante, foi também constatado por Bicelli et al. (1987) no Pará.

Quanto aos inimigos naturais, Torrend \& Zehntner (1917) foram os primeiros a comentar que a presença da formiga "caçarema" Azteca chartiflex spiriti Forel mantinha os cacaueiros livre da "mosquilla" e Bondar (1939) considerou a mesma formiga benéfica ao cacaueiro por defender a planta de ataque de Monalonion. Os predadores, Podisus sp. (Pentatomidae) e Heza sp. (Reduviidae) foram citados como inimigos naturais de M. dissimulatum em lavouras de cacau na Colômbia (Bustos \& Reyes, 1973). Além dos predadores específicos ocorrem outros generalistas, principalmente formigas que podem controlar vários insetos em um cacaueiro onde estejam estabelecidos, conforme constatado por Valenzuela-Gonzales et al. (1995) em plantações de cacau no México, onde a formiga E. tuberculatum é um importante agente de controle natural de pragas do cacaueiro.

Para o controle químico de Monalonion, Abreu (1979) citou vários produtos como eficientes. Por ser o Monalonion um inseto frágil e fácil de ser controlado, os resultados obtidos para o controle de outros insetos, foram também, muitas vezes, transferidos para o seu próprio controle (Abreu, 1977). Visando um controle racional da praga Abreu et al. (1989) apresentaram um manejo de monalônio, onde se prevê a amostragem quinzenal, no período crítico para a cultura do cacau, com a finalidade de identificar e controlar a praga nos focos iniciais. 


\section{2 Preferência alimentar de M. annulipes}

O mirídeo M. annulipes, tem no cacaueiro seu principal hospedeiro (Cubillos, 1984). São poucas as plantas descritas como hospedeiras para o inseto. Entwistle (1972) citou: Begonia convulvulaceae, B. vitifolia, Cecropia sp., Crotalaria sp., Hamelia patens na Costa Rica e segundo o mesmo autor, no Brasil várias plantas foram citadas para outras espécies de Monalonion, como: Cecropia adenopus para $M$. atratum; Hamelia erecta para M. bahiense e Anacardium occidentale, Ficus sp., $H$. erecta, $B$. convulvulaceae e $B$. vitifolia para $M$. shaefferi. Contudo não se encontraram registros de estudos de preferência alimentar realizados com diferentes hospedeiros para esses insetos. Como M. annulipes, não ocorre nos cacauais da Bahia, onde mais se cultiva cacau, o inseto foi pouco estudado e aparentemente, no Brasil, só foi citado em três hospedeiros além do cacaueiro: Rubus sp. (Abreu,1979), goiabeira Psidium guajava em São Paulo (Mendes, 1995) e cupuaçu Theobroma grandiflorum em Rondônia (Laker \& Trevisan, 1992), onde a planta sofre danos semelhantes aos causados no cacaueiro.

\subsection{Atividade da formiga E. tuberculatum}

A atividade exploratória diária de formigas foi primeiro estudada em cacauais na África onde foram observados o comportamento e os padrões de distribuição desses insetos por Majer (1976a; 1982). No Brasil, a distribuição de formigas foi descrita para plantações de cacau na Bahia, sugerindo-se uma diferença marcante à encontrada na África, onde predominam outras espécies de formigas (Leston, 1973; Majer et al., 1994). Dentro de um sistema ecológico como uma lavoura de cacau estabelecida e em fase produtiva, poucas são as formigas dominantes. Medeiros et al. (1995) mapearam e 
amostraram um hectare de cacaueiros no Sul da Bahia e três espécies de formigas foram consideradas dominantes: Azteca chartiflex spiriti, E. tuberculatum e Wasmannia auropunctata, entre as 40 avaliadas. A formiga $E$. tuberculatum vem ultimamente sendo estudada em cacauais da Bahia pela sua importância como um possível agente de controle biológico de pragas (Hora et al., 1997). Observou-se que na região citada as colônias dessas formigas podem ser monogínicas, quando contêm uma única rainha, ou poligínicas, quando há muitas rainhas. Em 42 colônias avaliadas, 21 eram monogínicas, 18 poligínicas e em três colônias as rainhas não foram encontradas. Um maior número de indivíduos encontrado em colônias poligínicas sugere que uma das causas da ocorrência de múltiplas rainhas seria aumentar a eficiência de defesa e/ou a força de forrageamento da colônia (Vilela et. al., 1997). Essa mesma formiga foi encontrada em cacauais do México onde se observou que exerce atividade de forrageamento nas 24 horas do dia e em seus ninhos foram encontrados restos de 11 ordens de insetos (Valenzuela-Gonzales et al., 1997). Entretanto, a importância das formigas predadoras em lavouras de cacau deve ser melhor avaliada, especialmente em Rondônia, onde nessa avaliação encontrou-se a formiga capturando diversos insetos inclusive monalônio. Sendo assim são necessárias também informações precisas da época de ocorrência de $M$. annulipes, da sua preferência por diferentes plantas hospedeiras e seu potencial de danos associados à fenologia do cacaueiro. 


\section{DINÂMICA POPULACIONAL DE Monalonion annulipes SIGNORET, 1858 (HEMIPTERA: MIRIDAE) EM CACAUEIROS DE ARIQUEMES, RO}

\subsection{Introdução}

$\mathrm{O}$ inseto Monalonion annulipes, um mirídeo conhecido por monalônio, é considerado uma das principais pragas para o cacaueiro Theobroma cacao L. no Município de Ariquemes, Estado de Rondônia, onde altas infestações têm sido observadas (Mendes, 1988). Este inseto ataca principalmente frutos e ramos novos de cacau, cupuaçu e goiaba, provocando em conseqüência, perdas de frutos e secamento de ramos (Abreu, 1977; Laker \& Trevisan, 1992; Mendes, 1995). O inseto também está associado à ocorrência de doenças no cacaueiro, que se instalam nos ferimentos de alimentação (Villacorta, 1973). Ocorre em vários países americanos e no Brasil não foi citado para a principal região produtora de cacau. a Bahia, mas é de ocorrência generalizada na Amazônia brasileira (Carvalho, 1972). Na Bahia, onde ocorrem várias espécies desse mirídeo, o seu manejo foi proposto por Abreu et al. (1989). Como não existem para Ariquemes informações precisas da época de ocorrência da espécie e seu potencial de danos associados à fenologia do cacaueiro, realizou-se esta pesquisa, com o objetivo de determinar a flutuação populacional do inseto; quantificar o ataque em frutos nas suas diferentes fases de desenvolvimento e registrar o ataque em ramos, nos picos de lançamento anual de ramos novos, que possam ocorrer. 


\subsection{Material e métodos}

O levantamento populacional de $M$. annulipes foi realizado em três lavouras produtivas de cacaueiros híbridos em Ariquemes, RO, no período de março de 1990 a março de 1993. Amostraram-se 25 cacaueiros em cada uma das três plantações, as quais apresentavam deficiência de sombreamento definitivo. Registrou-se a cada quinzena, o número de insetos nos frutos, até dois metros de altura. Os dados foram tomados sempre nas mesmas plantas e os insetos permaneceram no local após a avaliação. Os frutos foram distribuídos em 5 categorias: 1 = bilros, até $(3 \mathrm{~cm}$ de comprimento); 2 = frutos pequenos $(3$ a $7 \mathrm{~cm}) ; 3=$ frutos médios $(7$ a $13 \mathrm{~cm}) ; 4=$ frutos grandes $(>13 \mathrm{~cm}$ enquanto verdes) e $5=$ frutos maduros. Com essa classificação possibilita-se a obtenção da porcentagem média de frutos atacados para as distintas categorias, no período da frutificação à colheita da safra principal, sendo essa metodologia adaptada de Villacorta (1967) que utilizou somente frutos maiores e maduros para o estudo da população do inseto em cacau.

Para a verificação dos danos de $M$. annulipes, em diferentes fases de desenvolvimento, insetos foram individualizados sobre frutos protegidos (Figura 3.1) e para o estudo do comportamento, insetos em todas as fases de desenvolvimento foram liberados em um cacaueiro isolado, dentro de uma lavoura (Figura 3.2). Para a avaliação de ataque nos ramos, fez-se a proteção prévia de quatro ramos por planta, um em cada quadrante, na época de lançamentos de ramos, utilizando-se tecido de filó branco com $80 \mathrm{~cm}$ de cada lado. Na quinzena seguinte esses eram desprotegidos e avaliados conjuntamente após 15 dias de exposição.

Os resultados foram analisados pela estatística descritiva (Iemma, 1992) e comparados aos dados meteorológicos de precipitação pluvial e umidade relativa, obtidos no posto meteorológico da Estação Experimental da Comissão Executiva do Plano da Lavoura Cacaueira, CEPLAC, em Ouro Preto do Oeste, RO. 


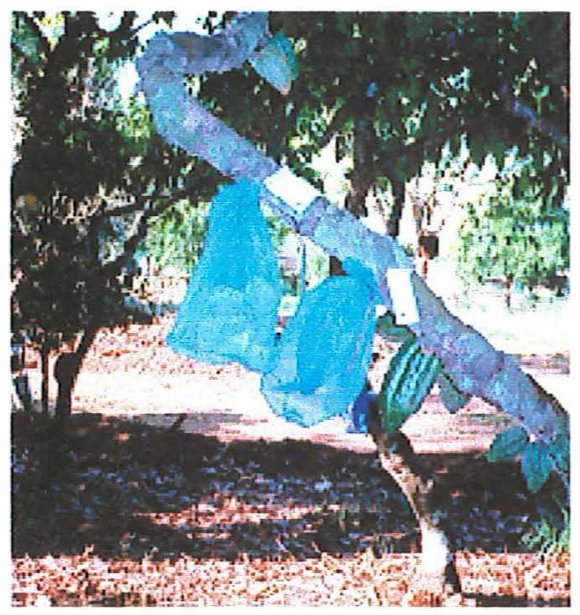

Figura 3.1. Frutos de cacau protegidos para avaliação de danos de M. annulipes.

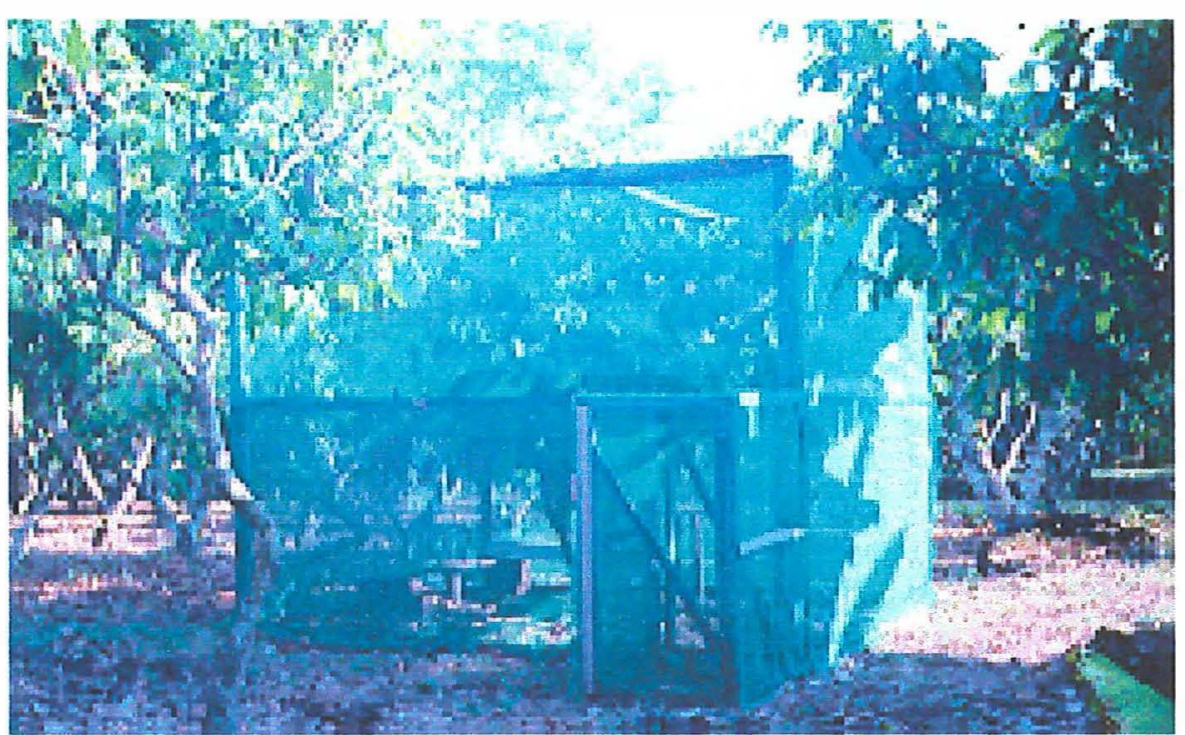

Figura 3.2. Cacaueiro protegido para avaliação do comportamento de M. annulipes. 


\subsection{Resultados e discussão}

Nota-se que o monalônio tem uma flutuação populacional caracterizada por um pico no mês de maio, praticamente desaparecendo de setembro a dezembro (Figuras 3.3). A população iniciou o crescimento quando a umidade relativa foi mais elevada, decrescendo depois do segundo mês de queda acentuada desse fator abiótico, estando de acordo com observações de Villacorta (1973), na Costa Rica.

Verifica-se que a distribuição mensal de frutos para as diferentes fases de desenvolvimento, se concentram entre os meses de janeiro e julho (Figura 3.4 e Tabela 3.1). A bilração, que é a formação inicial dos frutos, apresentou o pico no mês de fevereiro e os frutos pequenos foram encontrados em maior quantidade no mês de março. Os frutos médios e verdes foram encontrados em maior quantidade no mês de abril e a maioria dos frutos maduros nos meses de abril, maio e junho. Analisando-se conjuntamente as Figuras 3.3 e 3.4 , constata-se que a maior população da praga coincide com a maior disponibilidade de frutos em todos os estágios de desenvolvimento da safra principal do cacaueiro, para a referida região.

\subsubsection{Ataque de $M$. annulipes na frutificação do cacaueiro}

Observa-se que os frutos das categorias bilros, pequenos e maduros foram mais atacados no mês de julho com ocorrência de 5,7\%; 15,7 \% e $37,8 \%$, respectivamente, enquanto que para os frutos médios e verdes o maior ataque foi em maio com $32,6 \% \mathrm{e}$ $35,6 \%$ de incidência, respectivamente ( Figura 3.5 e Tabela 3.2). 


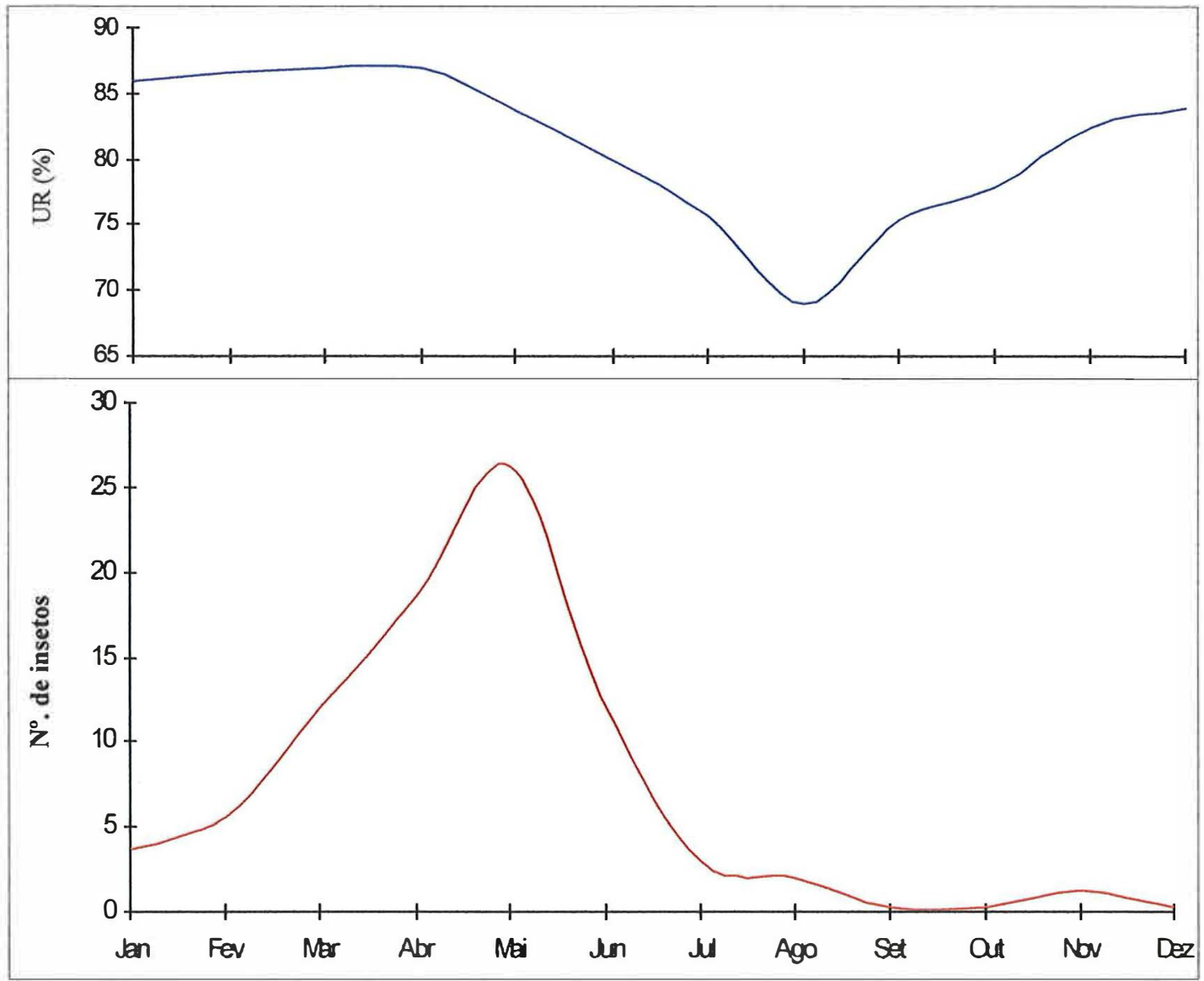

Figura 3.3. Umidade relativa e flutuação populacional de $M$. annulipes (adultos e ninfas) em cacauais, Ariquemes, RO. Médias mensais, março de 1990 a março de 1993. 
Observa-se que a porcentagem de frutos atacados pelo $M$. annulipes durante o período da safra aumentou, acompanhando o desenvolvimento dos frutos, sendo os frutos mais velhos mais atacados que os mais novos. O maior número de insetos foi registrado nos frutos verdes, na fase intermediária de desenvolvimento. Quanto à tolerância ao ataque, constatou-se que os frutos menores foram mais sensíveis aos danos do inseto, do que aqueles mais desenvolvidos. Em testes preliminares um inseto adulto impediu o desenvolvimento de um bilro quando nele se alimentou por dois dias consecutivos, mas aparentemente um inseto não causa danos econômicos, quando se alimentar pelo mesmo período em frutos já formados.

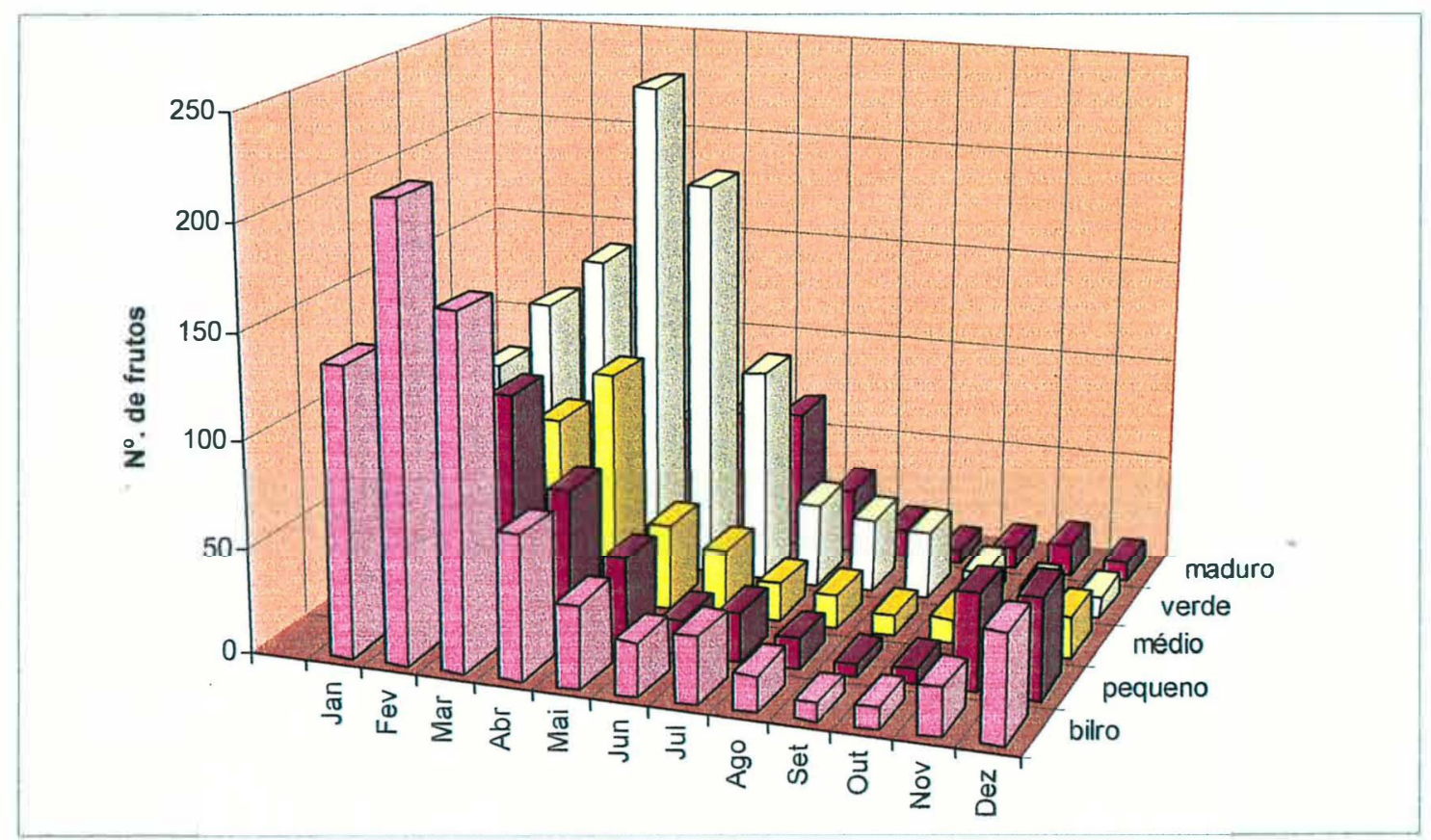

Figura 3.4. Disponibilidade de frutos de cacaueiro em diferentes fases de desenvolvimento. Ariquemes, RO. Médias mensais, março de 1990 a março de 1993. 
Tabela 3.1. Frutos de cacaueiro encontrados em diferentes fases de desenvolvimento. Ariquemes, RO. Médias mensais, março de 1990 a março de 1993.

\begin{tabular}{lrrrrr}
\hline Mês & Bilro & Pequeno & Médio & Verde & Maduro \\
Janeiro & 138 & 53 & 34 & 95 & 3 \\
Fevereiro & 215 & 113 & 75 & 127 & 15 \\
Março & 167 & 114 & 88 & 152 & 50 \\
Abril & 68 & 72 & 111 & 238 & 60 \\
Maio & 39 & 42 & 41 & 192 & 65 \\
Juno & 25 & 16 & 32 & 103 & 67 \\
Julho & 31 & 23 & 19 & 41 & 31 \\
Agosto & 17 & 14 & 16 & 36 & 13 \\
Setembro & 8 & 6 & 10 & 33 & 7 \\
Outubro & 10 & 8 & 11 & 16 & 10 \\
Novembro & 23 & 46 & 6 & 10 & 15 \\
Dezembro & 50 & 47 & 19 & 10 & 9 \\
\hline - & & & & & \\
\hline
\end{tabular}

$\mathrm{Na}$ Figura 3.6, estão ilustradas as diferentes fases de desenvolvimento do inseto sobre frutos de cacau. Pode-se visualizar que são insetos aparentemente frágeis e na fase de ninfa ficam geralmente agrupados em determinadas partes do fruto, causando danos desde o primeiro ínstar. Quando ocorre alta umidade, foi verificada maior movimentação das ninfas que podem atacar qualquer parte do fruto, mas em horas mais quentes do dia, são mais comuns entre dois frutos ou entre o fruto e o caule da planta. Tais locais também protegem os insetos durante as chuvas. 


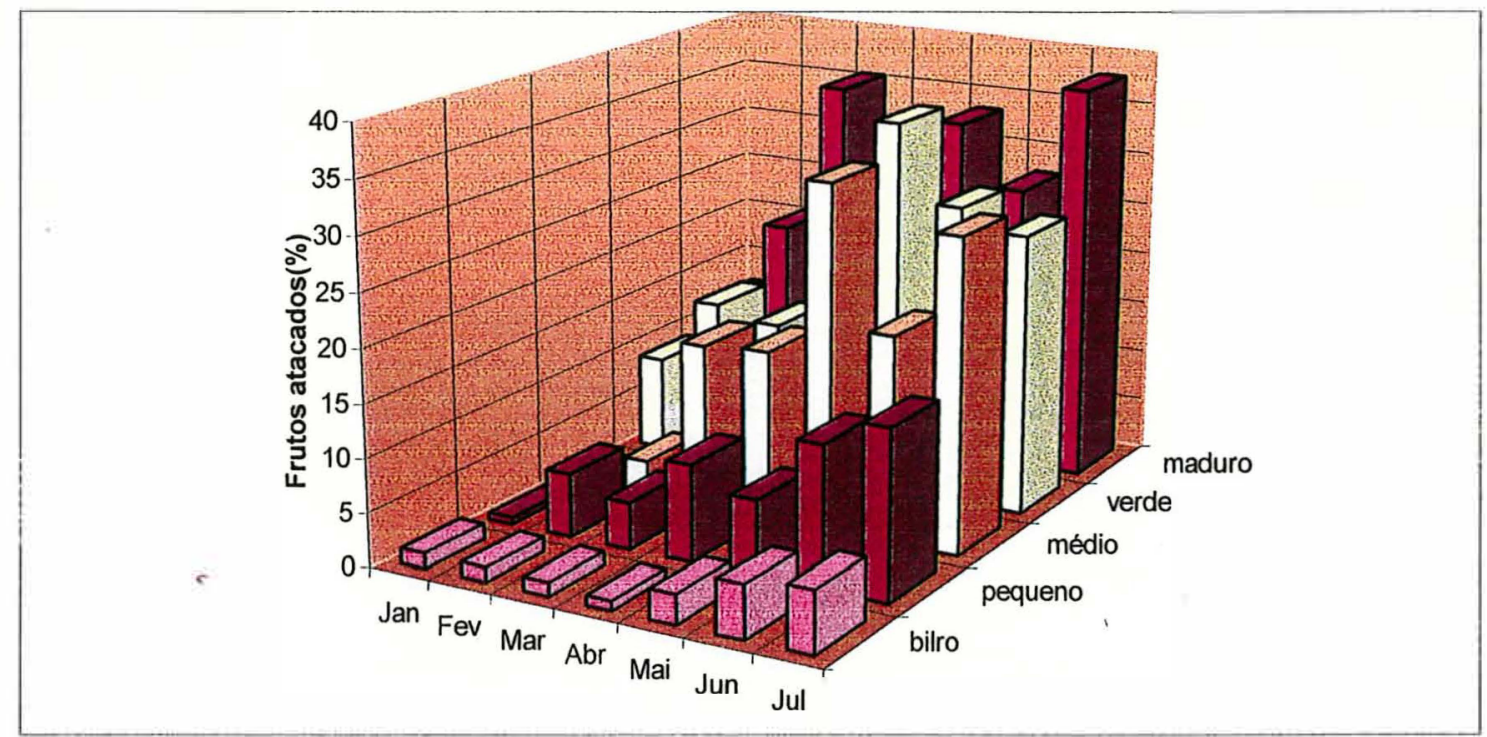

Figura 3.5. Porcentagem de frutos de cacaueiro atacados por M. annulipes em diferentes estágios de desenvolvimento. Ariquemes, RO. Médias mensais, 1990 a 1993.

Tabela 3.2. Porcentagem de frutos de cacaueiro atacados por $M$. annulipes em diferentes estágios de desenvolvimento. Ariquemes, RO. Médias mensais, 1990 a 1993.

\begin{tabular}{lccccc}
\hline Meses & $\begin{array}{c}\text { Bilro } \\
(\%)\end{array}$ & $\begin{array}{c}\text { Pequeno } \\
\mathbf{( \% )}\end{array}$ & $\begin{array}{c}\text { Médio } \\
\mathbf{( \% )}\end{array}$ & $\begin{array}{c}\text { Verde } \\
\mathbf{( \% )}\end{array}$ & $\begin{array}{c}\text { Maduro } \\
\mathbf{( \% )}\end{array}$ \\
\hline Janeiro & 1,5 & 0,6 & 0 & 9,0 & 12,0 \\
Fevereiro & 1,4 & 6,0 & 3,3 & 15,6 & 20,5 \\
Março & 1,3 & 4,4 & 15,6 & 14,4 & 35,4 \\
Abril & 0,9 & 9,1 & 16,0 & 23,1 & 19,6 \\
Maio & 2,7 & 7,0 & 32,6 & 35,6 & 33,2 \\
Junho & 4,9 & 13,1 & 19,4 & 28,4 & 27,4 \\
Julho & 5,7 & 15,7 & 29,3 & 26,5 & 37,8 \\
\hline
\end{tabular}



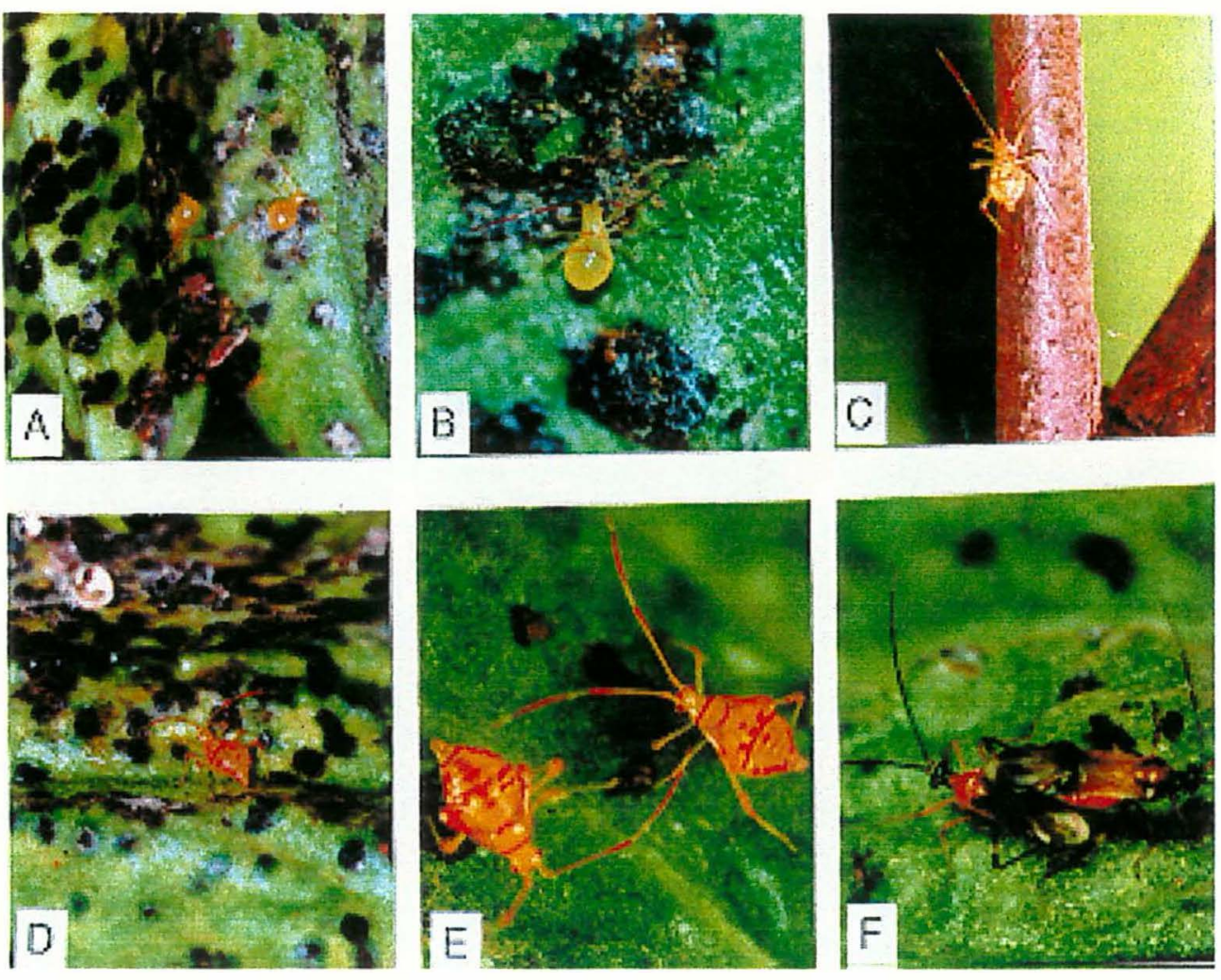

Figura 3. 6. Ninfas de $M$. annulipes em diferentes fases de desenvolvimento $(\mathrm{A}, \mathrm{B}, \mathrm{C}, \mathrm{D}, \mathrm{E})$ e adultos em cópula $(\mathrm{F})$.

Os danos mais freqüentes- provocados por M. annulipes em frutos de cacaueiro em todios os estágios de desenvolvimento, estão ilustrados na Figura 3.7, onde se verificam deformações, morte e rachaduras, quando em crescimento (A); fruto mumificado e com rachadura (B); picadas infectadas por fungos que encobrem o estágio de maturação (C), e um cacaueiro com frutos atacados pelo inseto (D). Esses danos foram mais comuns em ataques generalizados da praga, principalmente quando as colheitas foram realizadas em intervalos maiores que os tecnicamente recomendados para a cultura, mas também ocorreram com menor intensidade em áreas onde os intervalos quinzenais entre as colheitas foram obedecidos. Quanto ao comportamento de M. annulipes observado durante o teste nos frutos isolados e na planta protegida, verificou-se que se alimenta tanto a noite quanto de dia. A forma jovem apresentou 
comportamento alimentar distinto dos adultos, alimentando-se preferencialmente em determinada parte do fruto, caracterizado pela concentração de picadas. Os adultos foram encontrados se alimentando junto das colônias de ninfas e também isolados em frutos e brotos novos.

$\mathrm{Na}$ Figura 3.8, pode-se observar ataque em frutos maduros após terem completado o seu desenvolvimento. Desse modo fica caracterizado que os danos de $M$. annulipes para as condições de Rondônia são mais drásticos aos frutos de cacau do que aqueles comentados por Silva (1944); Garcia et al. (1985) e Abreu et al. (1989) que não citaram a ocorrência de perda de frutos desenvolvidos ou com mais de $8 \mathrm{~cm}$ de diâmetro, conforme se constatou nessa pesquisa.

Para as condições de Rondônia, também foram isolados 41 fungos que estavam associados aos danos de Conotrachelus humeropictus, inseto que broqueia os frutos do cacau na região (Laker at al., 1993). Ressalta-se que a broca ataca também na frutificação principal e no mesmo período de ocorrência do $M$. annulipes, com uma incidência próximo de $70 \%$ dos frutos broqueados (Trevisan, 1989). Assim muitas lavouras ficam simultaneamente atacadas pelas duas pragas. Portanto, os fungos citados para a broca podem também infectar os frutos atacados pelo monalônio na referida região.

As conseqüências desses ataques, associados a fungos repercutem também na colheita, onde se constatou que frutos maduros podem não ser colhidos por não exibir a sua coloração típica ou se colhidos podem estar em fase de maturação inadequada. A estratégia utilizada de se raspar o fruto antes da colheita, para verificar o seu estágio de maturação, não se mostra eficiente porque, neste caso, as lesões destroem os vestígios de coloração do fruto. 


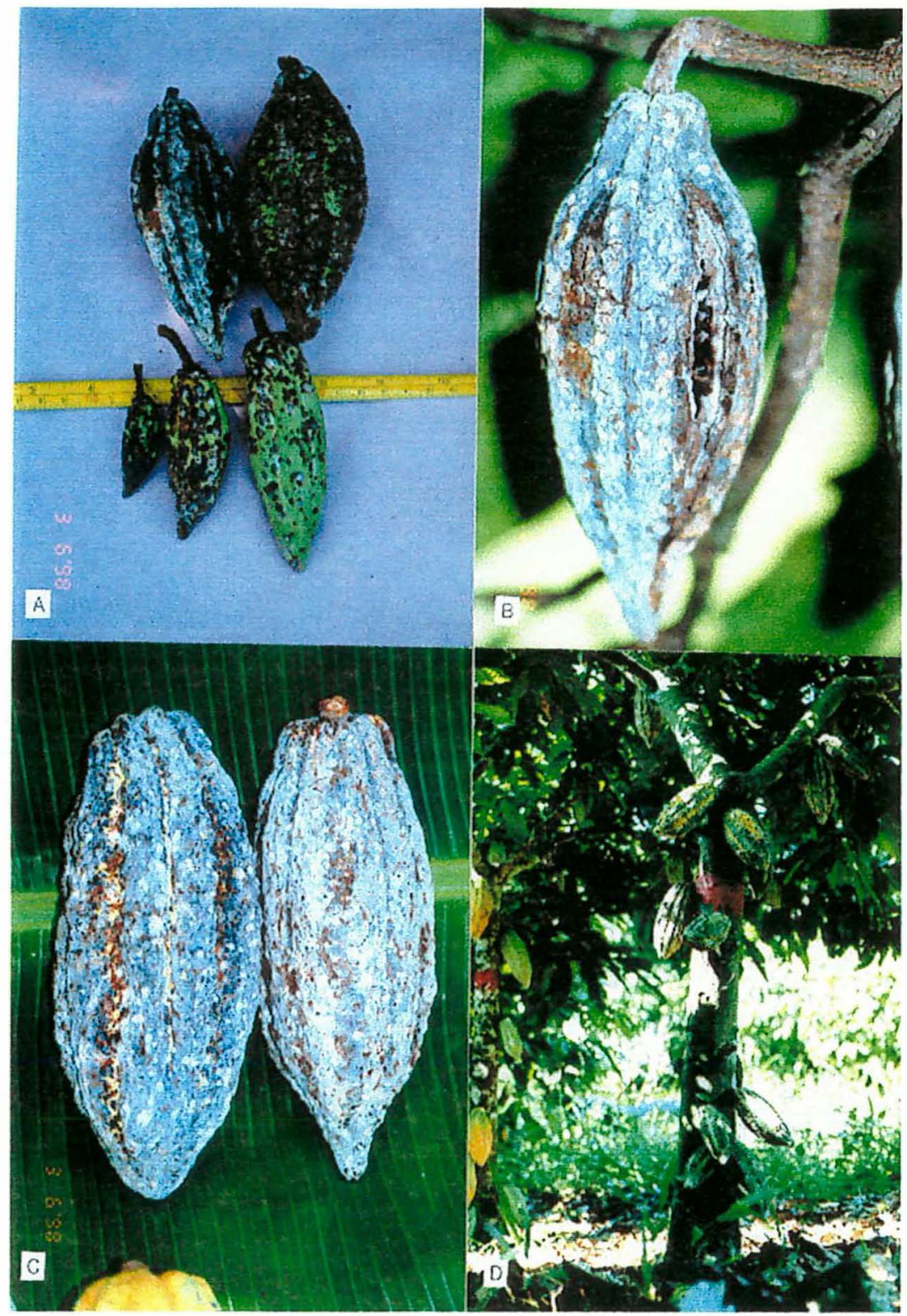

Figura 3.7. Ataque de $M$. annulipes em cacau: (A) deformação, rachaduras e mumificação em frutos em desenvolvimento; (B) fruto mumificado e com rachadura; $(\mathrm{C})$ frutos desenvolvidos e infectados por fungos após danos do inseto e (D) cacaueiro com frutos atacados. Ouro Preto do Oeste, RO.1998. 


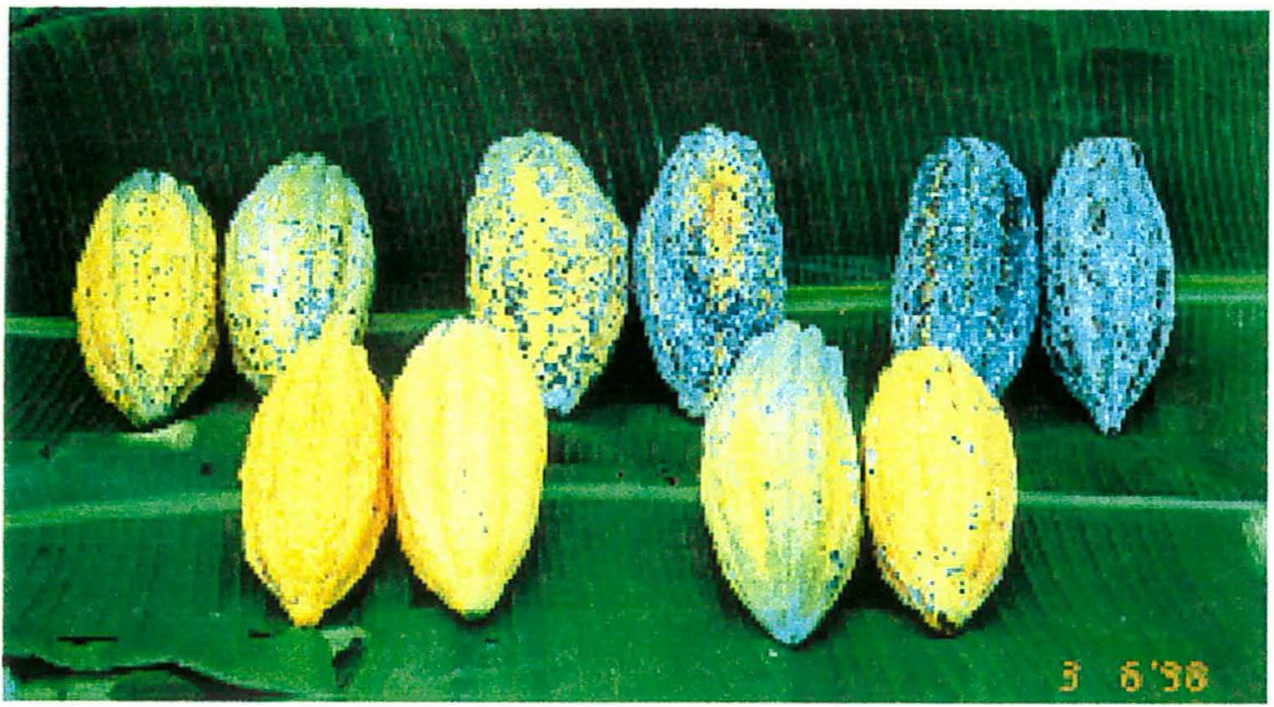

Figura 3.8. Frutos de cacau maduros atacados por M. annulipes após completado o seu desenvolvimento. Ouro Preto do Oeste, Rondônia.

Observando-se od danos de M. annulipes, verificou-se que houve morte de frutos em todas as fases de desenvolvimento, em conseqüência dos danos causados pelas picadas de alimentação e geralmente seguidas por infecção de fungos, que agravam os danos. De modo geral, se forem comparados alguns danos desse inseto citados para outros locais, para a mesma cultura, fica evidente que, em Rondônia, a praga causa maiores danos e é mais efetiva, pois em Ariquemes o inseto foi encontrado em todas as lavouras avaliadas durante os três anos de observação, indicando que uma vez estabelecida, a infestação pode se repetir nos anos subsequentes, quando nenhuma medida de controle for adotada. 


\subsubsection{Lançamento de ramos novos de cacaueiro e danos de $M$. annulipes}

O cacaueiro apresentou periodicidade para lançamento de novos ramos, distinguindo-se três picos de lançamentos de folhas novas, sendo o primeiro no mês de janeiro e os outros em maio e agosto (Figura 3.9). Verificou-se que muitas plantas lançaram ramos em assincronia durante os meses do ano, ocorrendo lançamentos de brotos novos em qualquer período do ano, sendo que essa característica da cultura do cacaueiro foi discutida por Alvim et al. (1974); Machado \& Alvim,(1981) e Almeida et al. (1987). A renovação de folhas do cacaueiro pode também apresentar variações mesmo dentro de uma mesma região, conforme se constatou em Ouro Preto do Oeste, quando em 1994 a renovação das folhas foi mais intensa em fevereiro, em pleno período chuvoso e outra no final do período seco, no mês de agosto (Silva \& Scerne, 1986). A temperatura média anual para a região foi de $24,5^{\circ} \mathrm{C}$ com as médias mensais entre 22,3 e $25,8^{\circ} \mathrm{C}$, durante o período.

Os danos de monalônio nos ramos de cacau (Figura 3.10) permitem observar folhas secas e lesões em ramos novos, causadas pela injeção de saliva tóxica nos tecidos, durante a alimentação do inseto. Ataques intensos e sucessivos na brotação nova, levam à desfolha total da planta conhecido por "queima" ou "emponteiramento" do cacaueiro. As partes atacadas ficam expostas a infecções por fungos que causam a morte descendente (Villacorta, 19973). 


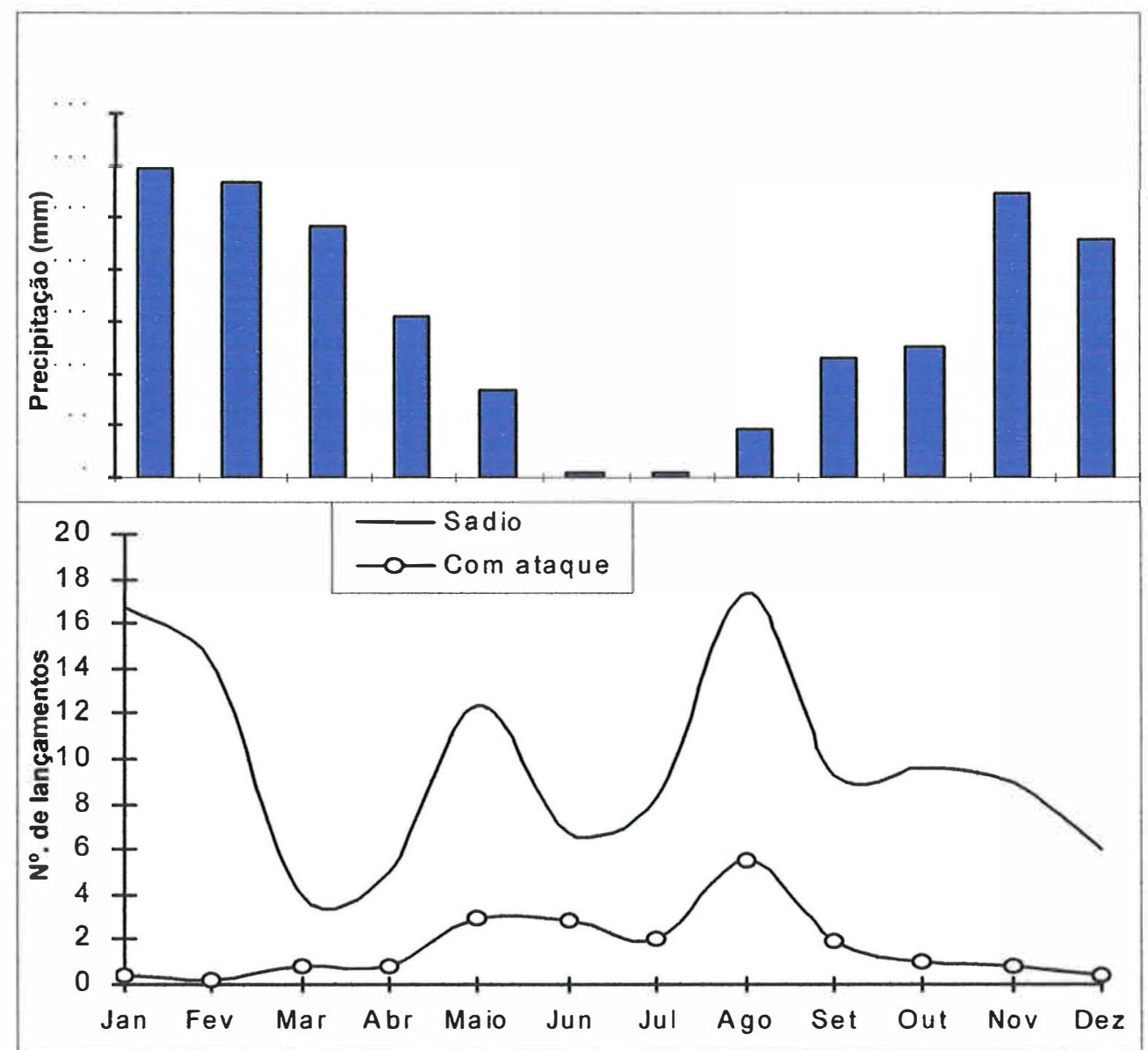

Figura 3.9. Precipitação pluviométrica, lançamento de ramos de cacaueiro e ataque de M. annulipes em Ariquemes, RO. Médias mensais, março de 1990 a março de 1993. 


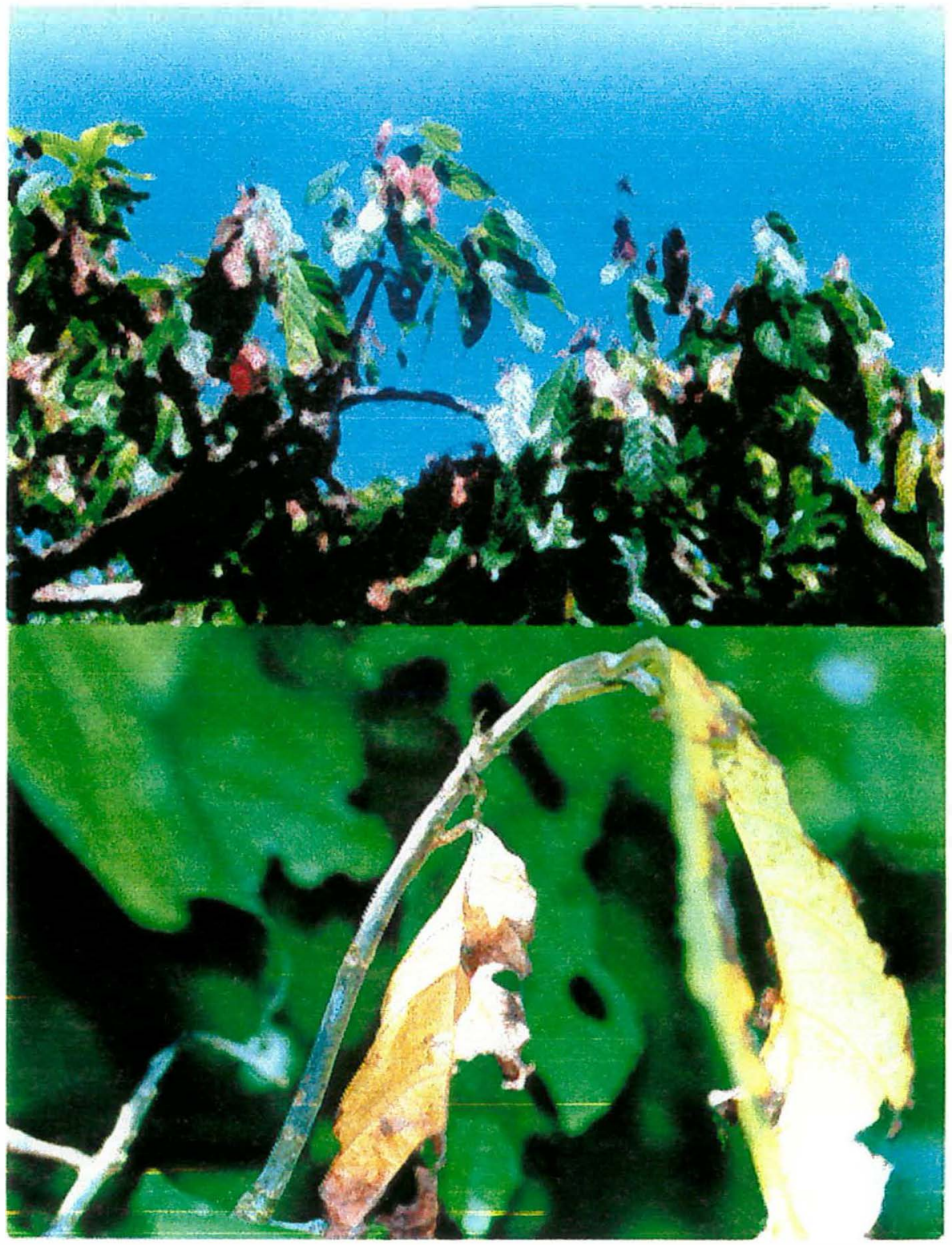

Figura 3.10. Danos de M. annulipes em lançamentos de ramos de Cacaueiro. Ouro Preto do Oeste, Rondônia. 


\subsubsection{Estratégia de manejo}

Com base na flutuação populacional de M. annulipes em Ariquemes e nos dados de fenologia da planta e nas variáveis climáticas, pode-se propor para esta região, um controle preventivo que depende de vistorias periódicas na lavoura, a cada quinzena, a partir de janeiro até maio, com a finalidade de encontrar e controlar os focos iniciais. $\mathrm{O}$ controle deve ser feito na fase de instalação do foco e consiste em pulverizar com inseticida adequado o local, abrangendo duas filas de cacau ao redor do foco inicial. Após quinze dias, retornar ao local para verificar se houve eclosão de novos insetos e se necessário, repetir o controle, com a finalidade de eliminar os insetos que possam ter emergido ou escapados do controle. Não querendo usar inseticidas pode-se também, nessa fase, tentar o controle removendo os frutos ou derrubando os insetos em desenvolvimento no chão, onde não conseguem completar o ciclo. Os frutos com pústulas são os mais prováveis de estarem com ovos e se forem em pequena quantidade podem ser removidos, evitando-se assim reinfestação. Após o mês de junho, provavelmente o controle químico em toda a área, seja economicamente inviável, porque a lavoura entra em final de safra (Figura 3.2) e com queda na frutificação. Em tais circunstâncias os poucos frutos que serão protegidos, poderão não cobrir os custos de controle, além do mais, nessa época a tendência é haver mais frutos desenvolvidos e esses toleram mais ao ataque do inseto. Colheitas mais freqüentes, quinzenais, conforme preconizado para a cultura, ajudam a conter a praga por retirarem juntamente com os frutos, ovos e ninfas. 


\section{PREFERÊNCIA ALIMENTAR DE Monalonion annulipes SIGNORET, 1858 (HEMIPTERA: MIRIDAE) EM HOSPEDEIROS ALTERNATIVOS}

\subsection{Introdução}

O conhecimento do comportamento de insetos e as suas relações com as plantas hospedeiras é uma necessidade básica visando o manejo de pragas em diferentes ecossistemas de cultivo, como os utilizados com o cacaueiro Theobroma cacao L. que apresenta melhor desempenho quando cultivado em consórcio com outras plantas. $\mathrm{O}$ mirídeo Monalonion annulipes tem nessa cultura seu principal hospedeiro (Abreu, 1979; Cubillos, 1984; Trevisan \& Mendes, 1993). As outras plantas descritas como hospedeiras deste inseto foram: Begonia convulvulaceae, B. vitifolia, Cecropia sp. Crotalaria sp. e Hamelia patens na Costa Rica (Entwistle, 1972), goiabeira Psidium guajava em São Paulo (Mendes 1995) e cupuaçu Theobroma grandiflorum em Rondônia (Laker \& Trevisan, 1992). No cacaueiro, o inseto ataca ramos novos e frutos e está também associado a doenças que infectam os locais danificados (Potes, 1952; Villacorta, 1967 e Rodrigues et al., 1993). A identificação de gêneros de mirídeos neotropicais da subfamília Bryocorinae pode ser realizada com auxílio da chave de identificação elaborada por Carvalho \& Ferreira (1995) e para a identificação das espécies do gênero Monalonion o caráter mais seguro é o estudo da genitália do macho (Carvalho, 1972). Para auxílio no controle de M. annulipes é necessário investigar os fatores associados a sua preferência por hospedeiros, como subsídio para o entendimento do seu comportamento (Eguagie, 1977). Como o cacaueiro e 


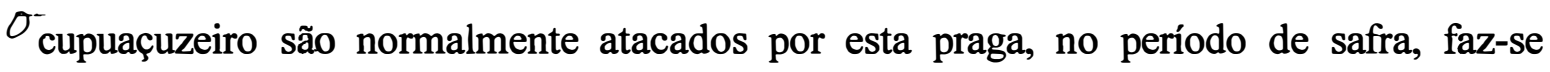
necessário o estudo das alternativas alimentares utilizadas pelo inseto para sobreviver em hospedeiros alternativos. Deste modo, o presente trabalho teve como objetivo obter o índice de preferência por frutíferas comuns na região e seus possíveis hospedeiros alternativos.

\section{2 Material e métodos}

Os experimentos foram realizados na Estação Experimental da CEPLAC em Ouro Preto do Oeste, RO, situada a 250 metros de altitude, localizado nas coordenadas S 1043'37,1" e W 62014'17,8", obtida pelo equipamento de bolso "Scoutmaster GPS", sendo o laboratório mantido à temperatura média $24 \pm 2{ }^{\circ} \mathrm{C}$ e umidade relativa $75 \pm 5 \%$.

\subsubsection{Hospedeiros alternativos}

Os testes foram efetuados em gaiolas de vidro quadradas medindo 40 centímetros de lado, com a frente e lado oposto fechado com tecido branco de náilon e fundo de compensado impermeabilizado de cor branca (Figura 4.1). No centro de cada gaiola, foi colocado um frasco com água e um chumaço de algodão tampando o frasco e em contato com o líquido, visando manter a umidade. Empregaram-se frutos de idade suscetível de uma coleção de fruteiras da Amazônia existente próximo à Estação Experimental, cuja relação consta da Tabela 4.1. Foram colocados frutos de cacau e outras fruteiras e liberados 50 indivíduos de $M$. annulipes em diferentes fases de desenvolvimento e após 72 horas os frutos foram avaliados, registrando-se o número de picadas de alimentação. Para a avaliação nos frutos do cupuaçu, foi necessário lavá-los em água com a finalidade de remover a pilosidade que encobria as manchas necrosadas, que correspondiam às picadas de alimentação. Assim que a pilosidade é removida, o fruto apresenta-se de coloração verde, que se altera rapidamente com a oxidação $( \pm 5$ minutos), ficando escurecido e dificultando o seu registro, após esse período. 


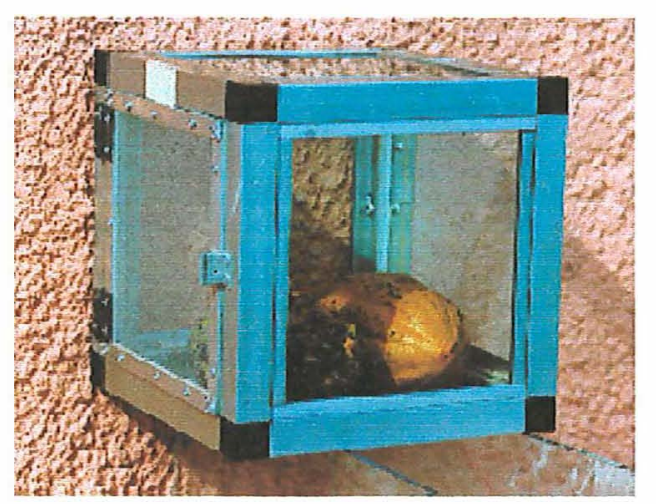

Figura 4.1. Gaiola utilizada para a avaliação da preferência alimentar de M. annulipes.

\subsubsection{Teste de preferência alimentar}

Em um teste de chance de escolha, determinou-se o Índice de Preferência (IP) (IP= T/P*100) adaptado de Reis Filho (1984) onde: IP= Índice de preferência de alimentação; $\mathrm{T}=$ Número de picadas de alimentação no material teste, e $\mathrm{P}=$ Número de picadas de alimentação no material padrão. Para a avaliação da preferência alimentar de M. annulipes frutos de cacaueiro foram utilizadas como padrão por serem o alimento preferido em todas as fases de desenvolvimento do inseto, conforme constatado em testes preliminares. Foram utilizadas cinco gaiolas, como descritas anteriormente, onde foram colocados frutos de cacaueiro, cupuaçuzeiro, cajueiro, bananeira cultivar Nanica, goiabeira e gravioleira e adicionadas três fềmeas adultas e três ninfas do quarto ou quinto instar, não sexadas, as quais foram deixadas nas gaiolas por 72 horas. Teve-se a preocupação de colocar uma quantidade semelhante em área e/ou volume de frutos expostos e manter a umidade relativa adequada, deixando no centro de cada gaiola um frasco com água tampado com algodão em contato com o líquido. A 
cada 12 horas, as gaiolas eram vistoriadas e os adultos recém emergidos ou eventualmente mortos durante o manuseio, eram substituídos. No final, fez-se a contagem do número de picadas de alimentação em cada material para determinação do índice de preferência.

\subsection{Resultados e discussão}

\subsubsection{Plantas hospedeiras}

Além do cacaueiro e do cupuaçuzeiro, foram danificadas outras oito espécies de fruteiras (araçá-pera, cajueiro, cruá, cacauí, bananeira, goiabeira, gravioleira e mangueira) (Tabela 4.1) as quais ainda não haviam sido citadas como hospedeiras de $M$. annulipes para a Amazônia. Essa constatação é de importância para a região, pois nos levantamentos de campo foram encontrados danos em cajueiro, araçá-pera, goiabeira e gravioleira, além dos hospedeiros já conhecidos. As fruteiras que no teste permitiram a sobrevivência do inseto, poderão ser danificadas pelo percevejo em determinado período do ano, principalmente, se forem plantadas em áreas próximas de lavouras de cacau ou cupuaçu. Com base na sobrevivência de insetos sobre frutos em condições de campo, o monalônio, pode apresentar alternativas para sobreviver nas plantas testadas, na falta do hospedeiro principal, talvez usando uma estratégia semelhante àquela utilizada por pentatomídeos, conforme detalhado por Panizzi (1997). Por outro lado, não deve ser descartada a alternativa da ocorrência de diapausa, conforme comentada por Masaki (1980) para hemípteros. Baseado nos estudos efetuados nas plantações de cacau e cupuaçu sugere-se que o $M$. annulipes esteja bem adaptado a essas culturas pois ocorre na maioria das lavouras, mesmo quando implantadas em áreas afastadas de plantas já constatadas como suscetíveis, o que sugere a existência de outros hospedeiros além dos encontrados nessa investigação. 
Tabela 4.1. Danos de alimentação de Monalonion annulipes em teste com livre chance de escolha entre fruteiras, ocorrência natural do inseto no campo e sobrevivência no hospedeiro. Julho a agosto de 1997. Ouro Preto do Oeste, RO.

\begin{tabular}{|c|c|c|c|c|}
\hline \multicolumn{2}{|c|}{ Plantas utilizadas para teste de alimentação } & \multirow{2}{*}{$\begin{array}{l}\text { Danos de } \\
\text { alimentação }\end{array}$} & \multirow{2}{*}{$\begin{array}{l}\text { Ocorrência } \\
\text { natural no } \\
\text { campo }\end{array}$} & \multirow{2}{*}{$\begin{array}{l}\text { Sobrevivência } \\
\text { no hospedeiro }\end{array}$} \\
\hline Nome comun & m Nome científico & & & \\
\hline Açaí & Euterpe oleracea Mart. & Não & Não & Não \\
\hline Abacate & Persea americana Mill. & Não & Não & Não \\
\hline Acerola & Malpighia glabra. L. & Não & Não & Não \\
\hline Araçá-boi & Eugenia stipitata Mc. Vough. & Não & Não & Não \\
\hline Araçá-pera & Psidium acutangulum DC. & Sim & Não & Sim \\
\hline Banana & Musa sp. & Sim & Não & Sim \\
\hline Caju & Anacardium occidentale L. & Sim & Sim & Sim \\
\hline Cacau & Theobroma cacao L. & Sim & Sim & Sim \\
\hline Cacauí & T. speciosum Willd. & Sim & Não & Sim \\
\hline Cruá & Sicana odorifera Naudin & Sim & Não & Sim \\
\hline Cupuaçu & T.grandiflorum (Willd.ex. Spring.) Schum. & Sim & Sim & Sim \\
\hline Goiaba & Psidium guajava $\mathrm{L}$. & Sim & Sim & Sim \\
\hline Graviola & Annona muricata L. & Sim & Sim & Sim \\
\hline \multicolumn{2}{|c|}{ Fruta-do-conde Annona squamosa $\mathrm{L}$. } & Não & Não & Não \\
\hline Laranja & Citrus sinensis L. & Não & Não & Não \\
\hline Limão & Citrus limon Burm. $\mathrm{f}$. & Não & Não & Não \\
\hline Mamão & Carica papaya $\mathrm{L}$. & Não & Não & Não \\
\hline Manga & Mangifera indica $\mathrm{L}$. & Sim & Não & Não \\
\hline \multicolumn{2}{|c|}{ Maracujá ácido Passiflora edulis Sims. } & Não & Não & Não \\
\hline \multicolumn{2}{|c|}{ Maracujá doce Passiflora alata Dryand. } & Não & Não & Não \\
\hline Pitanga & Eugenia pitanga L. & Não & Não & Não \\
\hline
\end{tabular}


Pelo resumo de informações de diferentes fontes (Tabela 4.2), verifica-se que as plantas hospedeiras citadas para os mirídeos do gênero Monalonion não abrangem muitas espécies, por falta de estudos do comportamento alimentar desses insetos. Abreu (1977) comenta que os insetos desse gênero se encontravam na vegetação natural da região cacaueira e quando o cacau foi introduzido na Bahia, muitos insetos passaram a atacar também esse hospedeiro. Assim para $M$. annulipes, além das plantas hospedeiras citadas, deverão ser acrescentadas as seguintes espécies:

$\begin{array}{ll}\text { Araçá-pera } & \text { Psidium acutangulum (Myrtaceae) } \\ \text { Caju } & \text { Anacardium occidentale (Anacardiaceae) } \\ \text { Cruá } & \text { Sicana odorifera (Cucurbitaceae) } \\ \text { Cacauí } & \text { Theobroma speciosum (Sterculiaceae) } \\ \text { Banana } & \text { Musa sp. (Musaceae) } \\ \text { Goiaba } & \text { Psidium guajava (Myrtaceae) } \\ \text { Graviola } & \text { Annona muricata (Annonaceae) }\end{array}$

Com bàse na literatura consultada (Tabela 4.2) das 17 espécies de Monalonion consideradas, sete foram citadas em cacau, porém algumas espécies foram descritas sem citação do hospedeiro e outras podem ter ocorrido simultaneamente em uma mesma área sem que essa associação fosse percebida. $O$ que permite inferir que existe um número maior de espécies que não foram citadas ainda em cacau. 
Tabela 4.2. Espécies válidas de insetos do gênero Monalonion e suas plantas hospedeiras.

\begin{tabular}{|c|c|}
\hline Espécies & Plantas hospedeiras \\
\hline $1-M$. annulipes Sgnoret, 1858 & $\begin{array}{l}\text { Cacau (Theobroma cacao), cupuaçu } \\
\text { (Theobroma grandiflorum), umbaúba } \\
\text { (Cecropia adenopus), goiaba (P. guajava) } \\
\text { begônia (B. convulvulaceae, B. vitifolia) } \\
\text { Crotalaria sp. giga (Hamelia patens) e } \\
\text { amora (Rubus sp.) }\end{array}$ \\
\hline $2-M$. atratum Distant, 1883 & $\begin{array}{l}\text { Cacau (T. cacao) umbaúba (C. adenopus) } \\
\text { e H. erecta }\end{array}$ \\
\hline $3-$ M. bicolor Carvalho \& Costa, 1988 & Abacate (Persea gratissima) \\
\hline $4-M$. bondari Costa Lima, 1938 & Cacau (T. cacao) \\
\hline 5-M. columbiensis Carvalho, 1984 & Ingá (Inga sp.) \\
\hline 6-M. decoratum Monte, 1942 & \\
\hline 7 - M. dissimulatum Distant, 1883 & Cacau (T. cacao) \\
\hline 8 - M. incaicus Carvalho, 1972 & \\
\hline 9 - M. itabunensis Carvalho, 1972 & Coletado em floresta \\
\hline $10-$ M. kirkaldy Bondar, 1939 & Cacau (T. cacao)umbaúba (C. adenopus) \\
\hline $11-$ M. paraensis Carvalho 1985 & \\
\hline $12-$ M. parviventre Herr.-Sch., 1850 & Cacau (T. cacao) e giga (H. patens) \\
\hline 13 - M. peruvianus Kirdaldy, 1907 & \\
\hline $15-M$. velezangeli Carvalho \& Costa, 1988 & Abacate $(P$. gratissima $)$ \\
\hline $16-M$. versicolor Distant, 1883 & \\
\hline 17 - M. schaefferi Stal, 1860 & $\begin{array}{l}\text { Cacau (T. cacao), caju (A. occidentale), B. } \\
\text { convulvulaceae, B. vitifolia, H. patens } \mathrm{e} \\
\text { H. erecta }\end{array}$ \\
\hline
\end{tabular}

Fonte, (Entwistle, 1972; Carvalho, 1972; 1985; 1990; Carvalho \& Costa, 1988;

Carpintero \& Carvalho 1993; Mendes, 1995). 


\subsubsection{Preferência alimentar}

$\mathrm{O}$ índice de preferência para alimentação de $M$. annulipes em diferentes hospedeiros pode ser observado na Figura 4.2, onde verifica-se que houve diferença significativa entre os frutos, evidenciando que há preferência por algum fruto, quando os mesmos são oferecidos simultaneamente. Os frutos mais preferidos além do cacau (100\%) foram: cupuaçu $(27,6 \%)$, caju $(11,9 \%)$ e banana $(7,5 \%)$, que não diferiram entre si, e os menos preferidos foram a goiaba $(1,3 \%)$ e a graviola $(0,6 \%)$.

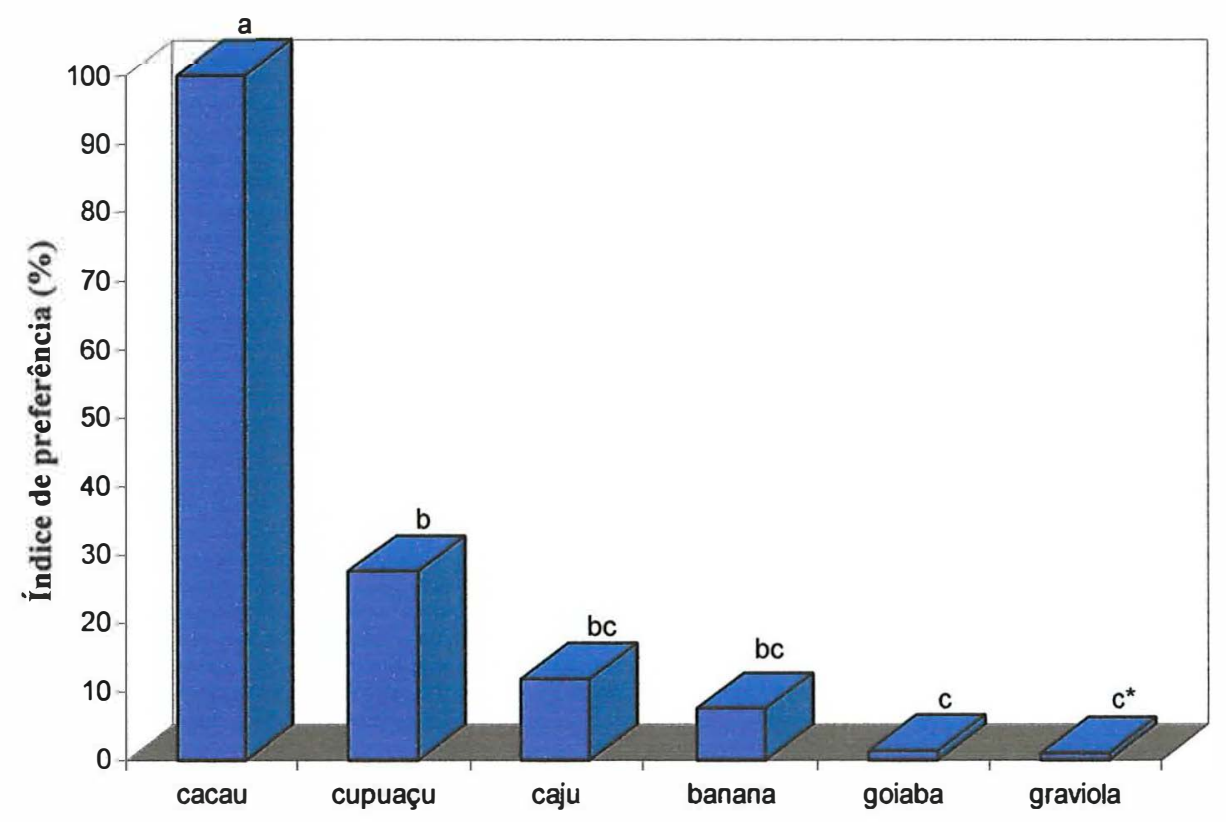

Figura 4.2. Índice de preferência de $M$. annulipes em diferentes hospedeiros. Ouro Preto do Oeste, RO, 1997. Temperatura $24 \pm 2^{\circ} \mathrm{C}$, UR: $75 \pm 5 \%$ e fotofase 13 horas.

* Letras distintas, diferença significativa a nível de $5 \%$ pelo Teste de Tukey. 
Nas observações de campo, as fruteiras mais atacadas foram o cacaueiro e a goiabeira, com danos característicos (Figura 4.3). Danos moderados também foram constatados em frutos de cupuaçuzeiro e cajueiro ( Figura 4.4). Não foram constatados ataques em bananeiras mesmo localizadas ao lado de plantios de fruteiras atacadas pela praga. Dentre todos os frutos de hospedeiros do inseto avaliados, os de goiabeira foram mais sensíveis às picadas de alimentação de $M$. annulipes. A constatação do ataque no campo não correspondeu exatamente com o teste de preferência em laboratório o que indica a ocorrência de outros fatores influenciando na seleção do hospedeiro em condições de campo, para o Estado de Rondônia. Segundo comentários de Reis Filho (1984), os fatores que governam a preferência alimentar possivelmente, não são os mesmos que condicionam a maior ou menor adequação ao desenvolvimento do inseto. Por outro lado, os frutos quando removidos das plantas perdem líquido e se apresentam fisiologicamente alterados, provocando comportamento distinto do inseto, o que pode ter influenciado sua alimentação. Foi também constatado que até a camada superficial de cera nos frutos interfere na decisão de insetos em dar ou não a picada de prova (Eingenbrode \& Espelie, 1995). Também deve-se considerar que os insetos são condicionados, conforme comentado por Becker (1965) a se alimentar dos frutos de cacau onde foram criados e o cacau fez parte do teste, como padrão de referência. Segundo informação de Crocomo (1983), o alimento ingerido em uma fase pode afetar a preferência alimentar até a geração seguinte. Tendo em vista que o teste necessita de um padrão de referência, escolheu-se o cacau por ser a cultura mais prejudicada; além do mais não foi possível, nesse período, manter insetos em número suficiente sobre hospedeiro neutro, a não ser cacau. Sendo assim, os insetos estavam condicionados a se alimentar no hospedeiro onde foram criados conforme quantificado no teste, onde a preferência foi por cacau. 




Figura 4.3. Danos de M. annulipes em frutos de cacaueiro e goiabeira. Ouro Preto do Oeste, RO. 1997. 
A escolha por ninfas dos últimos instares justificou-se porque, nessa fase causam mais danos (Villacorta, 1967), e podem apresentar preferência alimentar distinta dos adultos (Miller \& Wanzel, 1995) e a escolha de fêmeas adultas foi porque estas eram responsáveis pela escolha do hospedeiro para oviposição. Como o objetivo principal deste estudo foi estabelecer o índice de preferência, sendo o padrão, frutos de cacau, o teste deve ser considerado com as devidas ressalvas. Na forma jovem o M. annulipes, alimentou-se em determinada parte do fruto, caracterizado pela concentração de picadas, enquanto que os adultos, após cada alimentação, geralmente voavam e pousavam em outro local. Esse comportamento dos adultos pode permitir maior discriminação em testes de preferência alimentar. Observou-se também que a ninfa permaneceu preferencialmente no fruto onde deu a picada de prova. Assim, poderia estar se alimentando, dentre os frutos oferecidos, de um que não fosse o de melhor adequação alimentar, sendo isso em parte, devido a maior dificuldade de localização do hospedeiro nessa fase e da dificuldade em distinguir os odores misturados dentro da gaiola.

A identificação de diferentes plantas hospedeiras pode auxiliar no manejo da praga, indicando a presença do inseto em plantas que possam funcionar como plantas armadilha conforme proposto por Stern (1991).

Embora tenha sido registrados novos hospedeiros alternativos para M. annulipes em Rondônia, ainda não se tem conhecimento suficiente para indicar como o inseto sobrevive na região fora do período de frutificação do cacau. Porém como vários hospedeiros foram encontrados, talvez uma sucessão de hospedeiros seja utilizada pelo inseto e/ou em alguma fase de seu ciclo poderia ocorrer dormência ou diapausa, mesmo que esse fenômeno não seja citado em insetos tropicais, como estratégia de sobrevivência para mirídeos na Amazônia (Denlinger, 1986). 


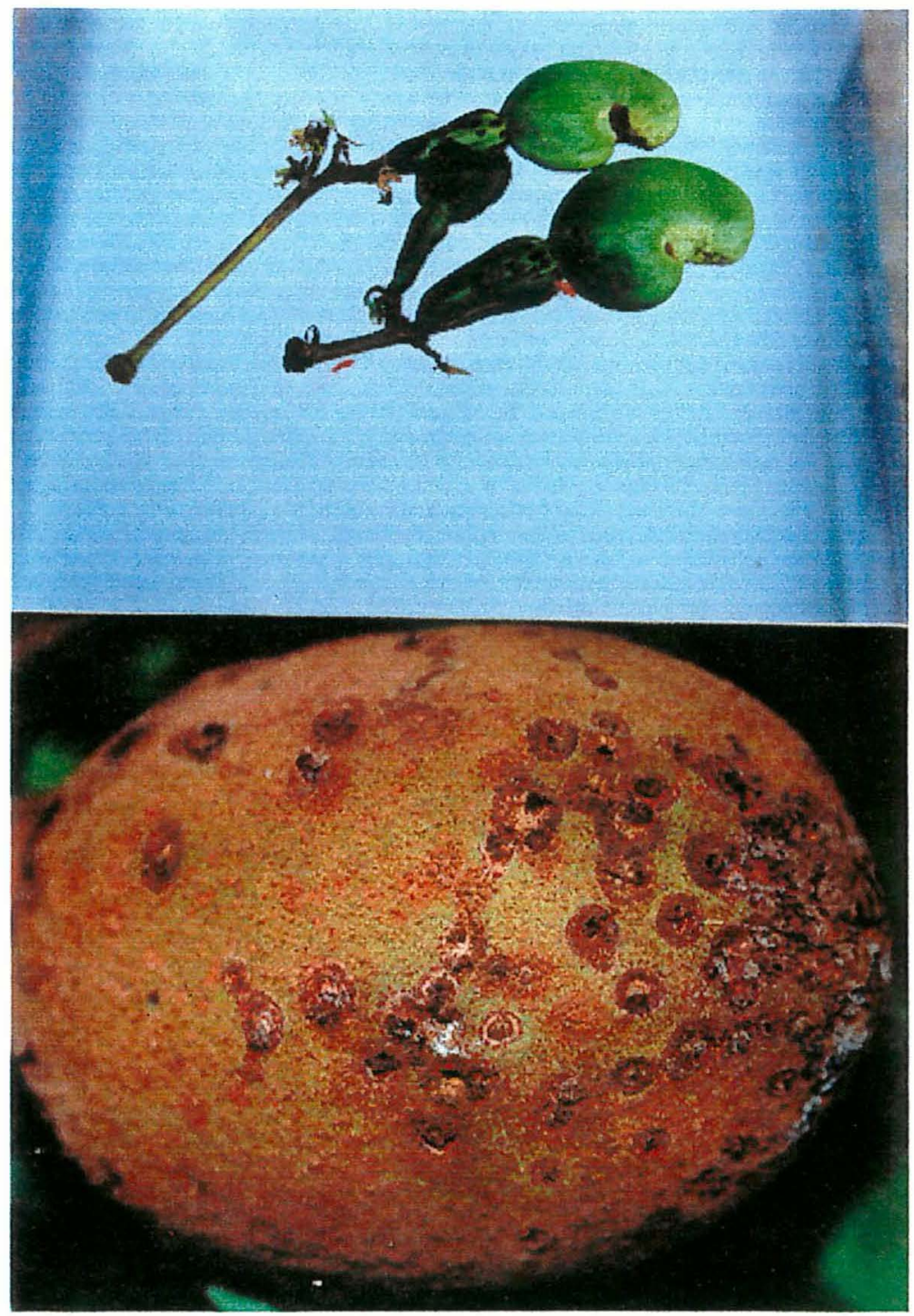

Figura 4.4 . Danos de M. annulipes em frutos de cajueiro e cupuaçuzeiro. Ouro Preto do Oeste, RO. 1997.

Como o cacaueiro, o cupuaçuzeiro e a goiabeira são normalmente atacados por esta praga, no período de safra principal, as informações aqui obtidas sugerem a continuidade e observações em outros períodos para determinar as possíveis alternativas utilizadas pelo inseto para sobreviver quando não ocorre frutificação nessas culturas. 


\section{ATIVIDADE DA FORMIGA Ectatomma tuberculatum OLIV. PARA O CONTROLE DO PERCEVEJO DO CACAU Monalonion annulipes SIGN.}

\subsection{Introdução}

A utilização de formigas predadoras para o controle de pragas em pomares foi de domínio dos chineses desde a antigüidade, mas apesar desse conhecimento milenar, esses insetos foram relativamente pouco estudados.

$\mathrm{Na}$ cultura do cacau, algumas atividades exploratórias diárias de formigas foram primeiramente estudadas em determinadas regiões cacaueiras da África, onde constataram que as árvores eram exploradas por uma sucessão de formigas influenciaram até na distribuição das principais pragas do cacau (Majer, 1976ab; Majer,1982).

No Brasil, a distribuição de formigas em cacauais da Bahia foi avaliada por Leston (1973) que encontrou padrão de distribuição distinto daquele encontrado na África e Medeiros et al. (1995) observaram que apenas três espécies de formigas são dominantes das 40 especies avaiiadas. Delabie (1989) realizou um levantamento com 300 espécies de formigas e constatou que, aproximadamente $95 \%$ delas eram benéficas ao cacaueiro. Muitas formigas predadoras são também protetoras de colônias de outros insetos e assim o conhecimento da relação de mutualismo entre formigas e colônias de insetos é necessário para a manipulação de ambos os organismos para controle de pragas de cacau (Ho \& Khoo, 1997). 
A formiga E. tuberculatum foi correlacionada negativamente com $\mathrm{o}$ cerambicídeo Steirastoma breve em cacauais da Venezuela por Jaffe et al. (1986), que recomendou a sua utilização como agente controlador de pragas. A mesma formiga foi também observada capturando insetos em plantações de cacau no México (ValenzuelaGonzales et al., 1998), mas ainda não está bem definida a importância das formigas predadoras em cacau, havendo necessidade de se iniciar estudos da atividade de $E$. tuberculatum que ocorre naturalmente em Rondônia.

O presente trabalho tem por objetivo verificar o padrão de distribuição dos ninhos, determinar o fluxo de atividade da formiga e quantificar a sua capacidade de predação, durante o período seco, em lavouras de produção de cacau.

\subsection{Material e métodos}

As observações foram realizadas no município de Ouro Preto do Oeste, $\mathrm{RO}$ em lavoura produtiva da área experimental de 35 hectares pertencente ao banco de germoplasma da Comissão Executiva da Lavoura Cacaueira (CEPLAC), onde as pragas foram controladas com inseticidas, quando necessário, em anos anteriores a este trabalho.

A formiga Ectatomma tuberculatum Oliver (Ponerinae) foi identificada pelo especialista Dr. Jacques H. C. Delabie, pesquisador da CEPLAC na Bahia.

\subsubsection{Distribuição dos ninhos da formiga E. tuberculatum em cacaueiros}

Para efetuar o levantamento da ocorrência de ninhos da formiga, foram examinados os cacaueiros de uma área de 2,5 ha e registrada sua localização em papel milimetrado, de modo a facilitar a medida da distância entre ninhos, a fim de determinar o tipo de distribuição, utilizando-se a técnica do vizinho mais próximo conforme Clark \& Evans (1954) e proposto por Silveira Neto et al. (1976), onde o Índice de Agregação é 
obtido pela fórmula $R=\frac{r a}{r e}$ sendo a distância observada $r a=\frac{\sum r a}{n}$, obtida pela soma da distância do vizinho mais próximo dividido pelo número de observações $n \mathrm{e}$

$$
r e=\frac{1}{\sqrt{\Delta}} \text { e } \Delta=\frac{N}{s}, \text { onde } N=\mathrm{n}^{\circ} \text { de ninhos e } s=\text { área. }
$$

$\mathrm{R}=2 \mathrm{ra} \sqrt{\Delta}$ (resultado próximo de zero, distribuição agregada; em torno de um, a distribuição é ao acaso e em torno de 2,15 distribuição uniforme).

$$
\text { Teste } \mathrm{C}=\frac{r a-r e}{\frac{\alpha}{\alpha} e} \operatorname{com} \frac{\operatorname{\alpha r} e}{\alpha}(5 \%)=1,96 .
$$

Como o Teste $\mathrm{C}$ apresentou valor negativo, aplicou-se o Teste de KolmogorovSmirnov na distribuição das freqüências das distâncias observadas, segundo Campos (1983).

\subsubsection{Atividade das formigas}

Para o registro do fluxo de formigas, foram escolhidos ao acaso dez formigueiros e contado o número de formigas que entravam no ninho por uma hora, semelhante ao método utilizado por Forti (1979) que denominou de fluxo positivo, o registro de formigas cortadeiras que passavam em direção ao ninho por um ponto, durante um minuto. Foram feitas dez repetições por ninho, com as leituras entre 8 e 11 horas e 14 às 17 horas, entre junho e julho de 1997, época que corresponde ao período seco do ano, para a referida região. Registrou-se o número total de formigas que entram com e sem alimento. Fizeram-se também algumas observações do comportamento geral da formiga durante sua atividade no cacaueiro. 


\subsubsection{Capacidade da formiga $E$. tuberculatum em evitar danos de monalônio}

Para quantificar a ação da formiga sobre $M$. annulipes, retiraram-se ao acaso 10 frutos maduros de cacau em três situações: a) frutos de plantas com ninhos estabelecidos; b) frutos de plantas de um cacaueiro vizinho mais próximo ao ninho (no espaçamento $3 \mathrm{~m} \times 3 \mathrm{~m}$, cada planta encontrava-se circundada por outras 4 eqüidistantes, consideradas as vizinhas mais próximas) e c) frutos fora do raio de influência direta das formigas localizados a partir de $9 \mathrm{~m}$ do ninho mais próximo. Foram realizadas 10 repetições para cada posição em relação ao ninho de formiga. Cada tratamento foi subdividido em três níveis de ataque nos frutos de cacau: sadio (sem pústulas ou bexigas); média infestação (com 1 a 50 pústulas) e alta infestação (com mais de 50 pústulas). A avaliação foi realizada em maio de 1998. Para a análise, aplicou-se o teste de contingência Qui-Quadrado, formulando-se a hipótese de que a formiga não interfiria no ataque do monalônio, de tal forma que os frutos de cacau seriam igualmente atacados pelos insetos.

\subsection{Resultados e discussão}

\subsubsection{Distribuição dos ninhos da formiga $E$. tuberculatum em cacaueiros}

O padrão de distribuição de ninhos dessa formiga pode ser constatado na Figura 5.1 e a análise estatística dessa distribuição pela Tabela 5.1 e Figura 5.2. 


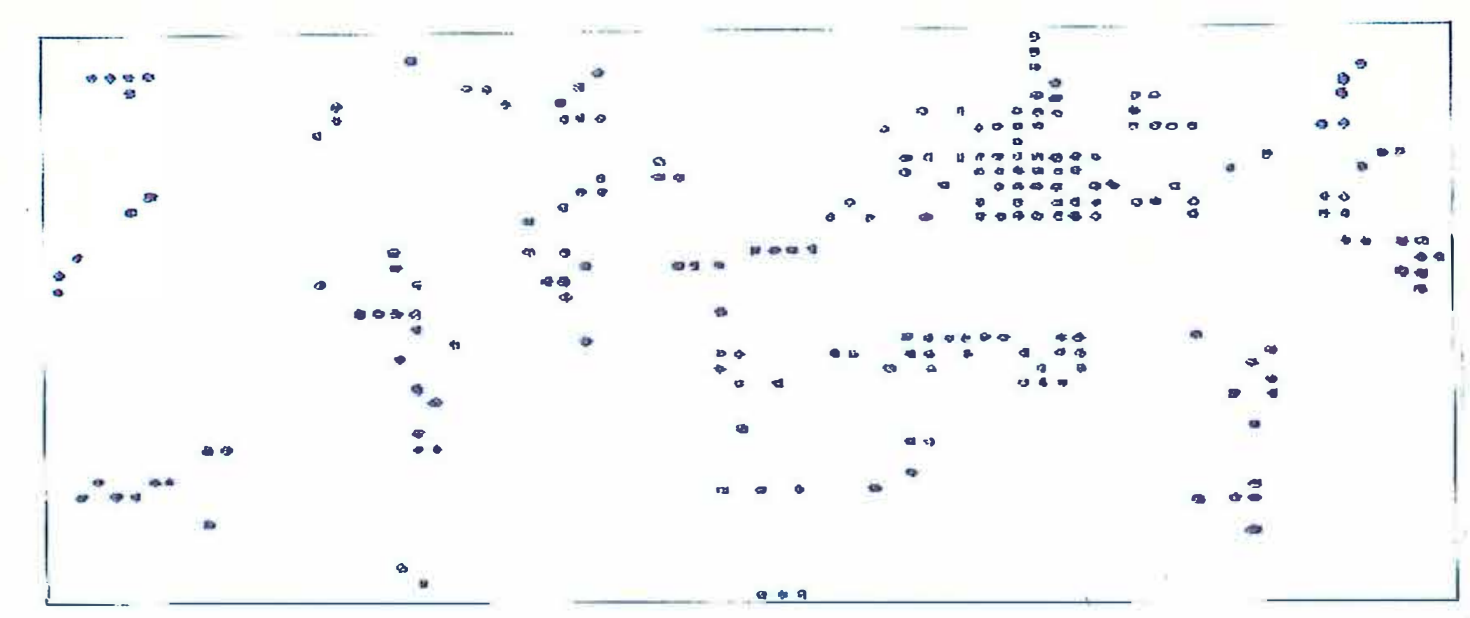

Figura 5.1. Distribuição dos ninhos de formiga Ectatomma tuberculatum (os pontos referem-se aos ninhos) em uma área de 2,5 hectares de cacaueiros em Ouro Preto do Oeste, RO.

Tabela 5.1. Distribuição de freqüências observadas em ninhos de formiga $E$. tuberculatum para o teste do vizinho mais próximo, em plantios de cacau em Ouro Preto do Oeste, RO. 1997.

\begin{tabular}{ccc}
\hline $\begin{array}{c}\text { Frequência observada } \\
(\mathrm{f})\end{array}$ & $\begin{array}{c}\text { Distâncias entre ninhos } \\
(\mathrm{m})\end{array}$ & $\mathrm{f} \times \mathrm{m}$ \\
\hline 158 & 3,00 & 474,00 \\
11 & 6,00 & 66,00 \\
2 & 9,00 & 18,00 \\
30 & 4,24 & 127,20 \\
10 & 6,70 & 67,00 \\
1 & 8,48 & 8,50 \\
3 & 10,82 & 32,50 \\
1 & 9,50 & 9,50 \\
\hline$\sum 216$ & & 802,70 \\
\hline
\end{tabular}

Vizinho mais próximo $\mathrm{R}=0,69$ Teste $\mathrm{C}=-0,31$ n.s 


\begin{tabular}{|c|c|c|c|c|c|c|c|}
\hline $\begin{array}{l}\text { STAT. } \\
\text { NONPAR } \\
\text { STATS }\end{array}$ & $\begin{array}{l}\text { Variable v } \\
\text { Kolmogorov } \\
\text { Ch1-square }\end{array}$ & $\begin{array}{l}\text { R1; dist } \\
\text { Smi movov }\end{array}$ & $\begin{array}{l}\text { ution: } \\
2888868 \\
=0,\end{array}$ & $\begin{array}{l}\text { atric p } \\
=\text { n.s. } \\
0\end{array}$ & 03571 & & \\
\hline $\begin{array}{l}\text { Upper } \\
\text { Boundary }\end{array}$ & $\begin{array}{l}\text { observed } \\
\text { freq-cy }\end{array}$ & $\begin{array}{l}\text { cumulatv } \\
\text { observed }\end{array}$ & $\begin{array}{c}\text { percent } \\
\text { observed }\end{array}$ & $\begin{array}{l}\text { cumul. } \\
\text { observed }\end{array}$ & $\begin{array}{l}\text { expected } \\
\text { freq-cy }\end{array}$ & $\begin{array}{l}\text { cumulatv } \\
\text { expected }\end{array}$ & $\begin{array}{l}\text { percent } \\
\text { expected }\end{array}$ \\
\hline $\begin{array}{r}0, \\
8, \\
16, \\
24, \\
32, \\
40, \\
48, \\
56, \\
64, \\
72, \\
80, \\
88, \\
96, \\
104, \\
112, \\
120, \\
128, \\
136, \\
144, \\
152, \\
\text { Infinity }\end{array}$ & $\begin{array}{l}0 \\
4 \\
2 \\
0 \\
1 \\
0 \\
0 \\
0 \\
0 \\
0 \\
0 \\
0 \\
0 \\
0 \\
0 \\
0 \\
0 \\
0 \\
0 \\
0 \\
1\end{array}$ & $\begin{array}{l}0 \\
4 \\
6 \\
6 \\
7 \\
7 \\
7 \\
7 \\
7 \\
7 \\
7 \\
7 \\
7 \\
7 \\
7 \\
7 \\
7 \\
7 \\
7 \\
7 \\
8\end{array}$ & $\begin{array}{r}0,00000 \\
50,00000 \\
25,00000 \\
0,00000 \\
12,50000 \\
0,00000 \\
0,00000 \\
0,00000 \\
0,00000 \\
0,00000 \\
0,00000 \\
0,00000 \\
0,00000 \\
0,00000 \\
0,00000 \\
0,00000 \\
0,00000 \\
0,00000 \\
0,00000 \\
0,00000 \\
12,50000\end{array}$ & $\begin{array}{r}0,0000 \\
50,0000 \\
75,0000 \\
75,0000 \\
87,5000 \\
87,5000 \\
87,5000 \\
87,5000 \\
87,5000 \\
87,5000 \\
87,5000 \\
87,5000 \\
87,5000 \\
87,5000 \\
87,5000 \\
87,5000 \\
87,5000 \\
87,5000 \\
87,5000 \\
87,5000 \\
100,0000\end{array}$ & $\begin{array}{r}.285714 \\
1,947397 \\
1,455795 \\
1,088294 \\
, 813565 \\
.608188 \\
, 454657 \\
, 339883 \\
, 254083 \\
, 189942 \\
, 141993 \\
, 106148 \\
, 079352 \\
, 059321 \\
, 044346 \\
, 033151 \\
, 024782 \\
, 018526 \\
, 013850 \\
, 010353 \\
, 030660\end{array}$ & $\begin{array}{l}, 285714 \\
2,233111 \\
3,688906 \\
4,777200 \\
5,590765 \\
6,198953 \\
6,653609 \\
6,993493 \\
7,247576 \\
7,437518 \\
7,579511 \\
7,685659 \\
7,765012 \\
7,824332 \\
7,868678 \\
7,901829 \\
7,926611 \\
7,945138 \\
7,958987 \\
7,969340 \\
8,000000\end{array}$ & $\begin{array}{r}3,57143 \\
24,34246 \\
18,19744 \\
13,60367 \\
10,16956 \\
7,60235 \\
5,68321 \\
4,24854 \\
3,17604 \\
2,37428 \\
1,77491 \\
1,32685 \\
, 99190 \\
, 74151 \\
, 55432 \\
, 41439 \\
, 30978 \\
, 23158 \\
117312 \\
, 12942 \\
, 38325\end{array}$ \\
\hline
\end{tabular}

\begin{tabular}{|c|c|c|c|}
\hline $\begin{array}{l}\text { STAT. } \\
\text { NONPAR } \\
\text { STATS }\end{array}$ & \multicolumn{3}{|c|}{$\begin{array}{l}\text { Variable VAR1, distribution: Geometric } p=, 03571 \\
\text { Kolmogorov-Smiknov } d=288868, p=n \cdot 8 . \\
\text { Chi-Square: - }\end{array}$} \\
\hline $\begin{array}{l}\text { Upper } \\
\text { Boundary }\end{array}$ & $\begin{array}{l}\text { cumul. } \\
\text { expected }\end{array}$ & $\begin{array}{l}\text { observd- } \\
\text { expected }\end{array}$ & \\
\hline $\begin{array}{r}0, \\
8, \\
16, \\
24, \\
32, \\
40, \\
48, \\
56, \\
64, \\
72, \\
80, \\
88, \\
96, \\
104, \\
112, \\
120, \\
128, \\
136, \\
144, \\
152, \\
\text { Infinity }\end{array}$ & $\begin{array}{r}3,5714 \\
27,9139 \\
46,1113 \\
59,7150 \\
69,8846 \\
77,4869 \\
83,1701 \\
87,4187 \\
90,5947 \\
92,9690 \\
94,7439 \\
96,0707 \\
97,0626 \\
97,8042 \\
98,3585 \\
98,7729 \\
99,0826 \\
99,3142 \\
99,4873 \\
99,6168 \\
100,0000\end{array}$ & $\begin{array}{r}-, 28571 \\
2,05260 \\
, 54420 \\
-1,08829 \\
, 18644 \\
-, 60819 \\
-, 45466 \\
-, 33988 \\
-, 25408 \\
-, 18994 \\
-, 14199 \\
-, 10615 \\
-, 07935 \\
-, 05932 \\
-, 04435 \\
-, 03315 \\
-, 02478 \\
-, 01853 \\
-, 01385 \\
-, 01035 \\
, 96934\end{array}$ & . \\
\hline
\end{tabular}

Figura 5.2. Análise estatística pelo teste de Kolmogorov-Smirnov da distribuição de ninhos de formiga E. tuberculatum, em cacauais de Ouro Preto do Oeste, RO.

Observa-se pelos resultados que a distribuição dos ninhos da formiga $E$. tuberculatum em cacauais de Rondônia, foi agregada (Figura 5.1)sendo que mostrou o valor para $p$ não significativo no teste de Kolmogorov-Smirnov, ou seja, não rejeita a hipótese de ser distribuição geométrica, havendo portanto indicação de dados agrupados (pois a distribuição geométrica é um caso particular de distribuição binomial negativa). Os pontos que representam cacaueiros com ninhos de formiga, quando agrupados estão a três metros de distância um do outro e representam $10 \%$ das plantas vivas da área. 
Um resultado próximo do encontrado nos cacauais da Bahia, embora não se tenham amostrado ninhos, mas sim plantas e nestas as formigas presentes constatadas em $24 \%$ dos cacaueiros (Medeiros et al, 1995). A porcentagem de plantas com ninhos de formigas na área avaliada em Rondônia, provavelmente seria maior, se não fossem utilizados inseticidas, para o controle de insetos nos anos anteriores ao levantamento. Constatou-se também que a formiga ocupou o solo e as plantas pela competição interespecífica e intra-específica por espaço, locais de nidificação e recursos conforme observado em estudos de Fowler et al. (1991).

\subsubsection{Fluxo e atividade das formigas}

O fluxo positivo de E. tuberculatum foi representado pela média de formigas por hora, de 10 formigueiros observados (Tabela 5.2).

Tabela 5. 2. Fluxo da formiga E. tubeculatum que entraram no ninho por hora. Ouro Preto do Oeste, RO. 1997.

\begin{tabular}{cccc}
\hline Ninhos & Fluxo médio & Com alimento sólido & Com líquido \\
\hline 1 & 54,4 & 10,4 & 5,1 \\
2 & 38,2 & 3,9 & 2,4 \\
3 & 24,7 & 2,9 & 4,8 \\
4 & 94,6 & 8,6 & 3,1 \\
5 & 12,3 & 1,9 & 0,5 \\
6 & 11,5 & 1,4 & 1,6 \\
7 & 23,6 & 2,7 & 0,5 \\
8 & 16,4 & 3,0 & 1,6 \\
9 & 31,6 & 6,3 & 0,7 \\
10 & 112,7 & 12,8 & 3,7 \\
Média & $42,0 \pm 35,2$ & $5,4 \pm 3,9$ & $2,4 \pm 0,7$ \\
\hline
\end{tabular}


Pelos dados nota-se que no fluxo médio de 42 formigas que retomaram ao ninho, $15,7 \%$ entraram com algum tipo de alimento, das quais aproximadamente $15 \%$ era de forma líquida, provavelmente coletado de partes da planta molhada pelo orvalho. $\mathrm{O}$ restante do alimento, considerado sólido, foi, na sua maioria parte de insetos, e eventualmente, fezes de lagartas e pedaços de frutos de cacau úmido.

As principais atividades das formigas forrageando o cacaueiro baseado em observações visuais, sem quantificar o tempo de cada indivíduo na atividade foram: busca; espera; mutualismo; vigilância e transporte de líquido.

Busca: nessa atividade observou-se que a formiga sai do ninho e percorre várias partes da planta, ou se dirige para o folhedo e vegetação rasteira efetuando pequenas paradas a procura de insetos. Encontrando uma presa tenta capturá-la, prendendo-a rapidamente com as mandíbulas e aplicando imediatamente uma ou mais ferroadas até imobilizá-la. As vezes, insetos grandes como lagartas (Figura 5.3) escapam da formiga caindo no solo. Nessa atividade, foram capturados todos os tipos de insetos inclusive, outros animais como aranhas, diplópodes e até mesmo pequenos moluscos. Cupinzeiros quando danificados dentro do raio de ação do formigueiro são facilmente localizados e nesse caso várias formigas saem do ninho e caminham com maior agilidade sem trilha estabelecida.

Os ninhos foram sempre localizados na base do cacaueiro e são típicos dessa formiga, pois apresentam uma "chaminé", construída basicamente de detritos orgânicos (Figura 5.4). 


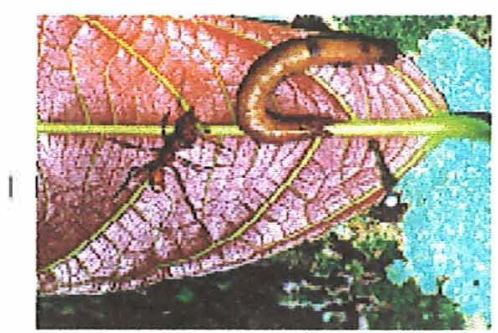

Figura 5.3. Formiga E. tuberculatum tentando capturar uma lagarta.

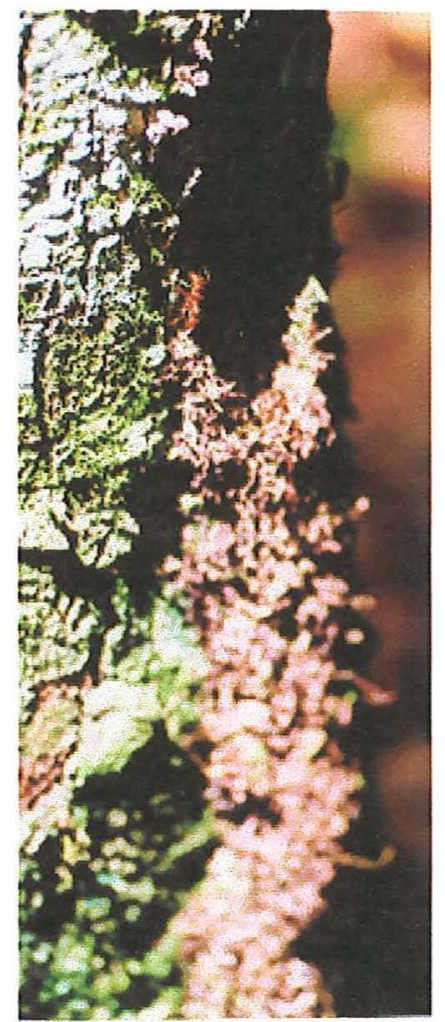

Figura 5.4. Entrada de um ninho de E. tuberculatum na base de um cacaueiro.

Espera: nesta atividade a formiga fica localizada em um ponto estratégico da planta com a cabeça erguida em relação ao plano de apoio, atenta à presença de insetos. 
Mutualismo: apesar de predadora a formiga E. tuberculatum também protege alguns insetos dos quais possa receber alimento. Foi observado que a maioria das colônias de homópteros estabelecida em frutos de cacau estavam protegidos pela formiga, durante o dia, mas durante a noite, algumas colônias de homópteros eram deixadas aos cuidados de outra espécie de formiga, confirmando as observações de Entwistle (1972) que citou E. tuberculatum, associado á colônias de pulgões.

Vigilância: ocorre na entrada do ninho e ao redor de colônias de homópteros, onde algumas formigas em determinados momentos circulam nesses locais, enquanto outras ficam em posição de ataque, provavelmente para assegurar a atividade sobre a colônia. Foi também observado que as formigas que fazem guarda na colônia, quando nessa atividade, não se interessam em capturar o inseto que se aproxima e levá-lo para o ninho, mas sim afastá-lo do local. Isso ficou constatado quando se ofereceu a essas formigas ninfas de monalônio, que foram atacadas de súbito com uma mordida mas, nem sempre capturadas e levadas para o ninho.

Transporte de líquido: foram observados formigas mantendo entre as mandíbulas, uma gota de líquido e as vezes pedaços molhados de matéria orgânica. Além dessas atividades outras também de importância podem ter ficado sem registro, principalmente aquelas realizadas em nível do solo, e interior do ninho e que foram em parte objeto de observação em outra espécie do gênero (E. permagnum) avaliada por Paiva \& Brandão (1989).

\subsubsection{Capacidade da formiga $E$. tuberculatum em evitar danos de monalônio.}

A ação de E. tuberculatum sobre $M$. annulipes pode ser visto na Figura 5.5, com a respectiva análise estatística. 


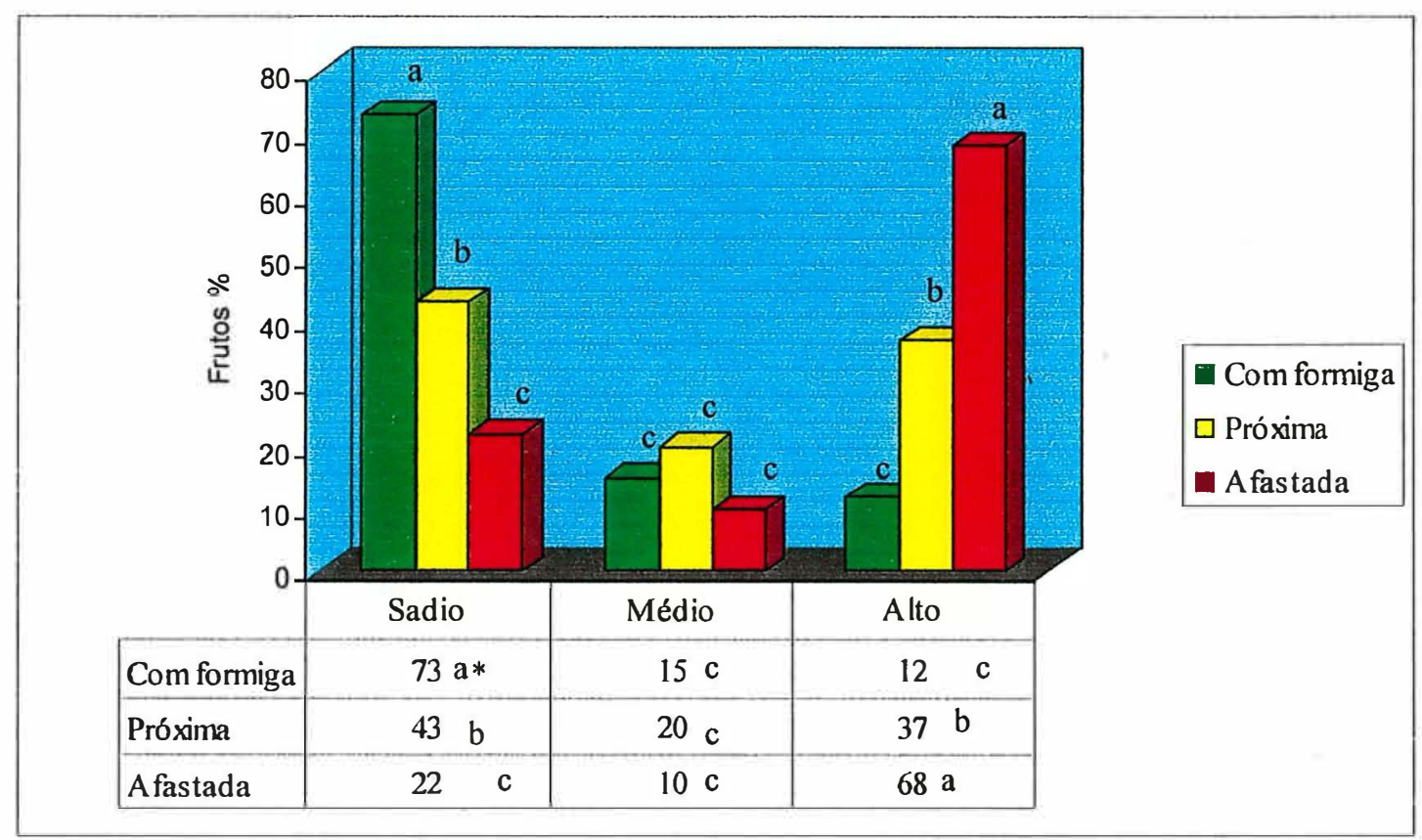

*Letras distintas diferem entre si ao nível de $1 \%$ de probabilidade. Teste Qui-Quadrado.

Figura 5. 5. Ação da formiga E. tuberculatum sobre ataque de monalônio em frutos de cacau encontrados em plantas com ninho da formiga, plantas próximas (3m) e afastadas (mais de 9 m). Ouro Preto do Oeste, RO. 1998.

Observa-se, que houve diferença estatística entre os níveis de alta infestação (frutos com mais de 50 picadas de alimentação) e os sadios e nesses mesmos níveis uma diferença entre as plantas com formigas e localizadas próximo ou afastada de um ninho dessas formigas. Também o que mais chamou a atenção foi que plantas com formigas tiveram um número significativo de frutos sadios a mais do que plantas sem formiga. Dos frutos colhidos nas plantas com formiga, $73 \%$ eram sadios e nas plantas afastadas (mais de $9 \mathrm{~m}$ ) somente $22 \%$ dos frutos estavam sadios, enquanto nas plantas vizinhas a porcentagem de frutos sadios foi de $43 \%$. Do total de frutos sadios avaliados nos três 
locais, $53 \%$ estavam nas plantas com ninho de formiga, $31 \%$ nas plantas próximas e $16 \%$ nas planta afastadas.

A formiga foi capaz de evitar os danos nos frutos de cacau e isso tem implicações econômicas que devem ser levadas em consideração, pois as plantas com ninhos de formigas tiveram um aumento de $51 \%$ na quantidade de frutos sadios. 


\section{CONCLUSÕES GERAIS}

Com base nos resultados de pesquisa com o mirídeo Monalonion annulipes em cacaueiros no Estado de Rondônia conclui-se que:

1. O inseto apresenta um pico populacional por ano nos meses de abril a junho;

2. A maior quantidade de insetos pode ser encontrada na frutificação que representa a safra principal, de maio a julho, onde causa danos em frutos de cacau de todas as idades;

3. É possível a identificação dos focos iniciais dos insetos a partir de janeiro até maio;

4. O M. annulipes tem hábito alimentar polífago, preferindo frutos e brotos novos de várias fruteiras;

5. Registram-se novos hospedeiros alternativos para M. annulipes em Rondônia:

$\bullet$

- $\quad$ bananeira (Musa sp.);

- $\quad$ cacauí (Theobroma speciosum);

- $\quad$ cajueiro (Anacardium occidentale);

- $\quad$ goiabeira (Psidium guayava);

- $\quad$ gravioleira (Anona muricata);

- $\quad$ cruá (Sicana odorifera); 
6. O ataque do $M$. annulipes em ordem crescente de preferência é: gravioleira; goiabeira, bananeira, cajueiro cupuaçuzeiro e cacaueiro;

7. A formiga $E$. tuberculatum tem distribuição agregada em $10 \%$ das árvores amostradas e habilidade para reduzir os danos causados pelo monalônio em cacaueiros.

8. As atividades comuns constatadas em E. tuberculatum são: busca; espera; mutualismo; vigilância e transporte de líquido, sendo que do fluxo de formigas que retornam ao ninho $15,7 \%$ entraram com algum tipo de alimento, dos quais cerca de $15 \%$ na forma líquida. 


\section{REFERÊNCIAS BIBLIOGRÁFICAS}

ABREU,J.M. Mirídeos neotropicais associados ao cacaueiro. In: LAVABRE, E.M. Les mirides du cacaoyer. Paris: Institut Français du Café et du Cacao, 1977. p.85-106.

ABREU,J.M. Mirídeos do cacaueiro. In: CURSO INTERNACIONAL DE CACAU, 4., Ilhéus, 1979. Ilhéus: CEPLAC, CEPEC, 1979. p.1-10.

ABREU, J.M.; NAKAYAMA, K.; BENTON, F.P. et al. Manejo de pragas do cacaueiro. Ilhéus: CEPLAC,CEPEC, 1989. 32p.

ALMEIDA,H.A; MACHADO,R.C.R.; NOVA,N.A.V.; SILVA, W.S. Influência de elementos meteorológicos no lançamento foliar do cacaueiro. Revista Theobroma, v.17, n.4, p.163-174, 1987.

ALVIM,P.T; MACHADO,A.D.; VELLO,F. Physiological reponses of cacao to environmental factors. Revista Theobroma, v.4, n.4, p.3-25, 1974. 
BASTOS,C.N.; EVANS, H.C. Ocorrência de "morte descendente" do cacaueiro no

Território Federal de Rondônia. Belém: CEPLAC,DEPEA, 1979. 6p. (Comunicado Técnico, 11).

BECKER,S.D, Resistence of plants to insects. Annual Review of Entomology., v.10, p.207-232, 1965.

BICELLI,C.R.L., SILVEIRA NETO,S.; MENDES,A.C.B. Dinâmica populacional de insetos coletados em cultura de cacau na região de Altamira, Pará. I. Levantamento das espécies. Revista Theobroma, v.17, p. 243-249, 1987.

BONDAR,G. Cancro dos fructos de cacau, causado por Monalonion xanthophylum, Walk "chupança de cacau". Rodriguesia, v.30, n.10, p. 179-186, 1937.

BONDAR,G. Notas entomológicas da Bahia. IV. Revista Theobroma, v.10, n.3, p.1-14, 1939.

BUSTOS,P,V.; REYES,Q.J.A. Flutuación de la población de Monalonion dissimulatum Distant (Hemiptera Miridae), enemigos naturals en cacao (Theobroma cacao L) en centro de Investigacion Agropecuarias. Palmira, Colombia, 1973. 63p. Thesis. (M.S.) Universidad Nacional de Colômbia, Faculdade de Ciencias Agrarias.

CAMPOS,H. Estatística experimental não-paramétrica. $4^{\mathrm{a}}$ ed. São Paulo: FEAQ 1983. 349p. 
CARPINTERO,D.L.; CARVALHO,J.C.M. An annoted list of the miridae of the Argentine Republic (HEMIPTERA). Revista Brasilleira de Biologia, v. 53, n.3, p.397-420, 1993.

CARVALHO,J.C.M. Mirídeos neotropicais CXLVI: Gênero Monalonion H. -S, 1853. Anais da Academia Brasileira de Ciências, v. 44, n.1, p.119-143, 1972.

CARVALHO,J.C.M. Mirídeos neotropicais CCLXII: Descriçõoes de um gênero e 11 espécies novas da América Central e América do Sul (Hemiptera). Revista Brasileira de Biologia, v. 45, n.4, p.653-668, 1985.

CARVALHO,J.C.M. Mirídeos neotropicais CCCXLV: Novas espécies de Chanchamayo, Perú, com lista anterior do mesmo paîs (Hemiptera). Revista Peruana de Entomologia, v.33, p.87-96, dic. 1990.

CARVALHO,J.C.M.; COSTA,L. A A. Mirídeos neotropicais CCCXCVII: Duas novas espécies do gênero Monalonion Herrich-Schaeffer (Hemiptera). Revista Brasileira de Biologia, v.48, n.4, p.893-896, 1988.

CARVALHO,J.C.M.; FERREIRA,P.S.F. Mirídeos neotropicais CCCXC: chave para os gêneros neotropicais de Bryocorinae Baerensprung, 1860 (Heteroptera). Revista Ceres, v.42, n.243, p.469-496, 1995.

CLARK,D.J.; EVANS,F.C. Distance to nearest neighbous as a mensure of spatial relationships in populations. Ecology, v.35, p.445-453, 1954.

CROCOMO,W.B. Consumo e utilização de milho, trigo e sorgo por Spodoptera frugiperda (J.E.Smith, 1797) Lepidoptera: Noctuidae. Piracicaba, 1983. 93p. Tese (Doutorado) - Escola Superior de Agricultura "Luiz de Queiroz", Universidade de São Paulo. 
CUBILLOS,G. El grajo amarrillo es tambien plaga de cacatales al sol. El Cacotero Colombiano, n.27, p.57-59, ago. 1984.

DELABIE,J.H.C. O paradoxo das formigas. Importância das pesquisas com formigas no Sudoeste da Bahia. Difusão Agropecuária, v.1, n.1, p.17-20, 1989.

DENLINGER,D.L. Dormancy in ropical insects. Annual Review of Entomology, v.31, p.239-264, 1986.

EGUAGIE,W.E. The biology of cocoa mirid control. In: INTERNATIONAL COCOA CONFERENCE, 6., Caracas, 1977. Caracas: ICC, 1977. p. 358-380.

EIGENBRODE,S.D.; ESPELIE, K.E. Efects of plant epicuticuticular lipids on insect herbivores. Annual Review of Entomology, v. 40, p.171-194, 1995.

ENTWESTLE,P.F. Pest of cocoa. London: Logman, 1972. 779p.

ENTWESTLE,P.F. Cocoa mirids; Part I. A world rewiew of biology and ecology. Cocoa Growers' Bulletin, n.5, p.16-20, 1985.

FORTI,L.C. Avaliação populacional das operárias forrageiras de Atta sexdens rubropilosa Forel, 1908 (Hymenoptera: Formicidae) através de dois métodos de estimativa. Piracicaba, 1979. 114p. Dissertação (Mestrado) - Escola Superior de Agricultura "Luiz de Queiroz", Universidade de São Paulo.

FOWLER,H.J.; FORTI,L.C.; BRANDÃO,C.R.F et al. Ecologia nutricional de formigas. In: PANIZZI,A.R.P.; PARRA,J.R.P. (Ed.) Ecologia nutricional de insetos e suas implicações no manejo de pragas. São Paulo: Manole, 1991. p.131-223. 
GARCIA,J.J.S.; MORAIS,F.I.O; ALMEIDA,L.C. et al. Sistema de produção do cacaueiro na Amazônia brasileira. Belém: CEPLAC,DEPEA, 1985. 118p.

HERNANDEZ,S.A.; PALMA,M.; PERDIQUE,A.R. Presencia de la "chinche" "mosquila" o çhupança do cacao (Monalonion dissimulatum Dist.) en Venezuela e su control. In: CONFERENCIA INTERAMERICANA DE CACAO,7. Palma, 1958. Palma: CIC, 1958. p.254-260.

HO,C.T.; KHOO,K.C. Partners in biological control of cocoa pests: Mutualism between Dolichoderus thoracicus (Hymenoptera: Formicidae) and Cataenococcus hispidus (Hemiptera: Pseudococcidae). Bulletin of Entomological Research, v.87, p.461-470, 1997.

HORA,R.R. da; DELABIE,J.H.C.; VILELA,E.F. Poligenia funcional em Ectatomma tuberculatum (Olivier) (Ponerinae). INTERNATIONAL PEST ANT SYMPOSIUM, 6, ENCONTRO DE MIRMECOLOGIA, 8. Ilhéus, 1997. Anais. Ilhéus:. UESC, 1997. p.96.

IEMMA,A.F. Estatística descritiva, Piracicaba: $\varphi O P, 1992.182 p$.

JAFFE, K,; TABLANTE,P.A.; SANCHEZ,P. Ecologia de Formicidae en plantaciones de cacao en Barlavento, Venezuela. Revista Theobroma v. 6, n.4, p.189-197, 1986. 
LAKER,H.A.; TREVISAN,O. The increasing importance of cupuassu (Theobroma grandiflorum) in the Amazon Region of Brazil. Cocoa Growers' Bulletin, n.45, p.45-54, 1992.

LAKER,H.A.; TREVISAN,O.; BEZZERRA,J.L. Fungi associated with pods of cocoa (Theobroma cacao L.) attacked by the borer Conotrachelus humeropictus Fiedler in Rondonia State, Brazil. Tropical Agriculture, v.70, n.4, p.332-336, Oct. 1993.

LESTON, D. The ant mosaic, tropical tree crops, and the limiting of pests and diseases. PANS, v.19, p.311-341, 1973.

LIMA,A.C. Sobre os percevejos do gênero Monalonion (Hemiptera: Miridae). Chacaras e Quintaes, v.57, n.3, p.519-525, 1938.

MACHADO,R.C.R.; ALVIM,P.T. Efeito da deficiência hídrica no solo sobre renovação de folhas, floração e estudo de água no cacaueiro. Revista Theobroma, v.11, n. 3, p.183-191, 1981.

MAJER,J.D. The ant mosaic in Ghana cocoa farms: further structural considerathions. Journal of Applied Ecology, v.13, p.145-155, 1976a.

MAJER,J.D. The maintenance of the ant mosaic in Ghana cocoa farms. Journal of Applied Ecology, v.13, p. 123-144, 1976 b. 
MAJER,J.D. The foraging activity of some West African cocoa farm ants. Revista Theobroma, v.12, n.3, p.155-162, 1982.

MAJER,J.D.; DELABIE,J.H.C.; SMITH,M.R.B. Arboreal and community patems in Brazilian cocoa farms. Biotropica, v.26, p.73-83, 1994.

MASAKI,S. Summer diapause. Annual Review of Entomology, v.25, p.1-25, 1980.

MEDEIROS,M.A.; FLOWLER,H.G.; DELABIE,J.H.C. O mosaico de formigas (Hymenoptera: Formicidae) em cacauais da Bahia. Científica, v.23, n.2, p.291-300, 1995.

MENDES, A.C.B. Relatório técnico de viagem ao pólo cacaueiro de Rondônia. Belém: CEPLAC/CORAM, 1988. $3 p$.

MENDES,A.C.B.; GARCIA,J.J.S. Biologia do besouro do cacau Steirastoma breve (Sulzer), (Coleoptera, Cerambycidae). Revista Theobroma, v.14, n.1, p.61-68, 1983.

MENDES,A.C.B.; GARCIA,J.J.S; ROSARIO,A.F.S. Insetos nocivos ao cacaueiro na Amazônia brasileira. Belém: CEPLAC,DEPEA, 1979. 34p. (Comunicado Técnico Especial, 1).

MENDES,A.C.B.; MAGALHÃES,B.P.; OHASHI,O.S. Biologia de Conotrachelus humeropictus, Fiedler, 1940 (Coleoptera: Curculionidae), praga do cacaueiro e do cupuaçuzeiro na Amazônia brasileira.Acta Amazônica, v.27.p135-144, 1997.

MENDES,P.F. Cultivo da goiabeira. Jaboticabal: FUNEP, 1995. 47p. 
MILLER,J.S.; WANZEL,J.W. Ecological characteristic and phylogeny. Annual Review of Entomology, v.40, p.389-415, 1995.

MORALES;M.; MATARITA,A. El capsidio del cacao y su importancia en el cultivo del cacao en Costa Rica. El Cacotero, v.3, n.5, p.11-14, 1961.

PAIVA,V.S.; BRANDÃO,C.R.F. Estudos sobre a organização social de Ectatomma permagnum Forel, 1908 (Hymenoptera Formicidae). Revista Brasileira de Biologia, v.49, n.3, p.783-792, 1989.

PANIZZI,A.R. Wild hosts of pentatomids: ecological significance and role in their pest status of crops. Annual Review of Entomology, v. 42, p.99-112, 1997.

POTES,A.F. Monalonion $s p$. plaga importante en el cacao del Valle del Cauca Colombia. Acta Agronomica, v.2, n.4, 183-193, 1952.

REIS FILHO,W. Influência de clones de seringueira na biologia e nutrição de Erinnyis ello ello (L.,1758) (Lepidoptera: Sphingidae). Piracicaba, 1984. 126p. Dissertação (Mestrado) - Escola Superior de Agricultura "Luiz de Queiroz", Universidade de São Paulo.

RODRIGUES,R.; PAIM,M.C.; CAMPOS,T.M., et al. Fungos associados a lesões de Monalonion bondari Costa Lima (HEMI., MIRIDAE) em frutos de cacau. In: CONGRESSO BRASILEIRO DE ENTOMOLOGIA, 14., Piracicaba, 1993. Resumos. Piracicaba: FEALQ, 1993. p.192. 
SILVA,I.C.; SCERNE, R.C.M. Fenologia do cacaueiro na Amazônia. CEPLAC/DEPEA. In: COMISÃO EXECUTIVA DO PLANO DA LAVOURA CACAUEIRA. Informe de pesquisa 1985. Belém, 1986. p. 2-4.

SILVA,P. Insect pest of cocoa in the state of Bahia, Brasil. Tropical Agriculture, v.22, n. 1, p.8-14, 1944.

SILVEIRA NETO,S; NAKANO,O; BARBIN,D. et al. Manual de ecologia dos insetos. São Paulo: Ceres, 1976, 419p.

STERN,V. Environmental control of insects using trap crops, sanitation, prevention, and harvesting. In: PIMENTEL,D.; HANSON,A.A. (Ed.) CRC. Handbook of pest management in agriculture. 2 ed. 1991, v.1, p.157-168.

TORREND,C. Insect and vegetable parasites of the cocoa-tree in State of Bahia, Brazil. Monthly Bulletin Agricultural International and Plant Disease, v. 9 p. 523-524, 1918.

TORREND,C.; ZEHNTNER,L. Moléstia do cacaueiro e a queima dos cacaueiros nos municípios de Ilhéus e Itabuna. Ilhéus: Associação Comercial de Ilhéus, 1917. 76p.

TREVISAN,O. Comportamento da broca dos frutos do cacau Conotracelus humeroictus Fiedler, 1940 (COL.: CURCULIONIDAE), Rondônia. Piracicaba, 1989. 57p. Dissertação (Mestrado) - Escola Superior de Agricultura "Luiz de Queiroz", Universidade de São Paulo. 
TREVISAN, O; MENDES, A.C.B. Flutuação populacional de Monalonion annulipes em cacauais de Rondônia. In: CONGRESSO BRASILEIRO DE ENTOMOLOGIA, 14., Piracicaba, 1993, Resumos. Piracicaba: FEALQ/SEB 1993. p.126.

VALENZUELA-GONZALES,J; LOPEZ-MENDEZ,A; LACHAUDT,J Activity patterns and foraging activity in nests of Ectatomma tuberculatum ( Hymenoptera: Formicidae) in cacao plantations. Southwestern Entomologist, v.4, n.20, p.507515, 1995. Resumo em CAB Abstracts on CD-ROM, 1997.

VENTOCILLA,J.A.; SIMITH,H.F.G.E.; SILVA,P. et al. Distribuição e flutuação da entomofauna nociva ao cacaueiro. In: Informe Técnico 1970/71. Comissão Executiva do Plano da Lavoura Cacaueira, Itabuna, 1972. p.61-52.

VILELA,E.F.; HORA,R.R. da; DELABIE,J.H.C. Composição de colônias de Ectatomma tuberculatum (Olivier) (Ponerinae). INTERNATIONAL PEST ANT SYMPOSIUM 6.; ENCONTRO DE MIRMECOLOGIA, 8., Ilhéus, 1997. Anais. Ilhéus: UESC, 1997. p.97.

VILLACORTA, A. Some studies on the biologiy and sazonal variation in the population of Monalonion annulipes Sig. in Costa Rica. Wisconsin, 1967. 35p. Thesis (M.S.) - Wisconsin of University.

VILLACORTA,A. Flutuacion anual de las poblaciones de Monalonion annulipes Sig. y su relacion com la "muerte descendente de Theobroma cacao" en Costa Rica. Revista Peruana de Entomología, v.16, n.1, p.21-24, 1973. 